\title{
Life Expectancy by Education, Income and Occupation in Germany: Estimations Using the Longitudinal Survival Method ${ }^{*}$
}

\author{
Marc Luy, Christian Wegner-Siegmundt, Angela Wiedemann, \\ Jeroen Spijker
}

\begin{abstract}
Reliable estimates for differences in life expectancy (LE) by socio-economic position (SEP), that can be assessed in an international context and are comprehensive in terms of considering different SEP dimensions, are missing for the German population so far. The aim of the present study is to fill this gap by providing estimates for differences in LE by education, household income, work status and vocational class. The lack of national mortality data by SEP required an innovative methodological approach to estimate LE from survey data with a mortality followup. The main strengths of the method are the low demand on the data, its simple applicability and the estimation of a set of age-specific probabilities of dying. We employed the method to the German Life Expectancy Survey and estimated period life tables for 45 male and 32 female SEP subpopulations. The results show striking differences in LE across all analysed SEP indicators. Among men, LE at age 40 ranges by more than five years between the lowest and highest household income quartiles, more than six years between individuals with low and high education, around ten years across the work status groups, and almost 15 years across the vocational classes. The proportion of those who reach the classic pension age of 65 years also varies considerably, as does the remaining LE at this age. The corresponding differences among women are smaller, yet still notable. The results yield an interesting finding for the ongoing discussion about the various consequences of an increased pension age. Moreover, they provide policy-makers, doctors, researchers and public health workers with insights into Germany's most disadvantaged SEP subpopulations and the potential extent of their disadvantages in terms of longevity and mortality.
\end{abstract}

Keywords: Life expectancy · Mortality · Socioeconomic position · Longitudinal survival method $\cdot$ Germany

This article contains supplementary material in the form of an online Appendix: DOI 10.12765/ CPoS-2015-17en, URL: http://www.comparativepopulationstudies.de/index.php/CPoS/article/ view/203/218. 


\section{Introduction}

Differences in lifetime by socioeconomic position (SEP) are some of the most studied phenomena in international mortality research. The social gradient in longevity - i.e., the higher the SEP, the lower the mortality - has been shown for nearly every industrialised society (e.g. Kunst 1997; Mackenbach et al. 1997; Spijker 2004). However, estimates for Germany are missing in most international comparative studies (see for instance the recent compilation of life expectancy by educational attainment for the European Union and Norway by EUROSTAT in Corsini 2010). This is due to the fact that official German population statistics do not provide data for mortality by SEP. Therefore, researchers who are interested in social differences in mortality in Germany must consult alternative data sources. Most commonly used are data from health insurances, pension registers and surveys with a mortality follow-up. Based on such data, the mortality gradient by SEP has also been confirmed for the German population for each of the three central dimensions of SEP, i.e. education, income and occupation (an extensive overview can be found in Lampert/Kro// 2014).

Due to the specific data situation in Germany, most studies analysing this topic provide results in terms of relative risks for specific age segments. For instance, Klein et al. (2001) found that among the 25-64 years old participants of the Augsburg MONICA study, the risk of dying decreases by 7.6 percent with every year of education. Such numbers are difficult to assess, however. This difficulty holds especially true for estimates on young and middle adult ages where the general level of mortality is low, and thus even small absolute differences in mortality can easily cause large relative differences. For most users of data on mortality differentials - such as public health workers and policy-makers - estimates for life expectancy (LE) would be more informative. Unfortunately, studies containing such estimates for the German population are rare. Most of them analyse differences in LE by income (e.g. Doblhammer et al. 2008; Kibele et al. 2013; Lampert/Kroll 2006; Lampert et al. 2007; Luy 2006; Perna et al. 2010; Shkolnikov et al. 2008; von Gaudecker 2006; von Gaudecker/Scholz 2007), but we found only six which present differences by education level (Doblhammer et al. 2008; Klein 1996, 1999; Luy 2006; Perna et al. 2010; Unger) Schulze 2013), and even less include estimates for LE by occupation status defined by main work status groups (Doblhammer et al. 2008; Luy 2006) or the basic differentiation between blue and white collar occupations (Kibele et al. 2013).

What makes the thin information on differences in LE by SEP in Germany even more limited is the fact that the existing studies are very heterogeneous with regard to the data and methods used as well as the definitions of the analysed subpopulations. We illustrate this briefly for the six studies providing estimates for differences in LE by education level. Four of them (Doblhammer et al. 2008; Klein 1996, 1999; Unger/Schulze 2013) are based on data of the German Socio-Economic Panel (SOEP), whose mortality follow-up has been demonstrated to be not representative for the mortality of the overall German population (Schnell/Trappmann 2006). The study conducted by Luy (2006) is based on data of the German Life Expectancy Survey (LES), and the study of Perna et al. (2010) on data of the Augsburg MONICA/ KORA study. The longevity indicators used in these publications range from LE at 
birth (Perna et al. 2010) to LE at age 16 (Klein 1996), at age 40 (Klein 1999; Unger/ Schulze 2013), at age 45 (Luy 2006) and at age 50 (Doblhammer et al. 2008). However, only Klein (1996) and Unger and Schulze (2013) derive these figures from the classical period life table approach. Klein (1999) presents estimates for educationspecific LE only for a further subdivision of the education groups by income and marital status. Perna et al. (2010) translate an estimated hazard function for the study sample on the basis of odds ratios into education-specific survival functions. Doblhammer et al. (2008) estimate how variations in the education level change the expected remaining life years of a reference person defined by specific characteristics with regard to marital status, work status, income, satisfaction with health and number of persons in the household. Luy (2006) performs cohort projections for individuals born between 1934 and 1952.

Another aspect which further complicates comparisons is that the six studies analyse different education levels, but none of them classifies the subgroups according to the internationally recognised ISCED scale: Klein (1996) presents estimates for the graduation levels of tertiary and below tertiary, Klein (1999) for minimum secondary and maximum primary, Luy (2006) for tertiary, secondary and primary, Doblhammer et al. (2008) for tertiary versus primary, Perna et al. (2010) for lower secondary and tertiary, and Unger and Schulze (2013) for tertiary, secondary and having no graduation (without presenting data for the primary level). As a consequence of these different approaches, the estimated variation in LE by education level varies considerably, ranging from 2.3 years (Perna et al. 2010) to 7.7 years (Unger/Schulze 2013) among men and from 1.9 years (Luy 2006) to 6.4 years (Dob/hammer et al. 2008) among women. Finally, all studies base their education-specific LE estimates on the assumption of age-invariant relative mortality risks, which were derived - with different methodological approaches - from survival experiences in young and mid-adult ages. This is questionable, because mortality differences by SEP have been shown to vary across ages and are usually higher in young and midadulthood than in older age groups (e.g. Zajacova et al. 2009).

The main point of this brief overview of existing estimates for differences in LE by SEP is that reliable estimates with regard to the extent of the differentials, that can be assessed in an international context, and that consider different SEP dimensions are missing for the German population. The aim of the present study is to fill this gap by providing estimates for differences in period LE by the three central SEP dimensions - education, income and occupation - which (i) refer to the same age segment, (ii) are derived from the same data, (iii) are based on a method which takes age-specific mortality patterns into account, and (iv) are easily accessible and applicable for further research. The lack of national mortality data by SEP in Germany requires the development of a methodological approach to estimate LE from survey data with a mortality follow-up. This method - to which we refer as the "Longitudinal Survival Method" (LSM) - is introduced in section 2 with its theoretical and formal derivation (section 2.1) and its implementation with the used LES data (section 2.2). The estimates for LE at ages 40 and 65 and the survival probabilities between these ages by education, income, and occupation are presented in section 3 . In section 4 we discuss the specific characteristics of the LSM in comparison to other 
approaches for estimating LE from longitudinal survey data (section 4.1) and summarise the most important results of this study in an international context (section 4.2). The paper ends with the final conclusions.

\section{The Longitudinal Survival Method (LSM)}

\subsection{Theoretical and formal derivation}

The development of the LSM was inspired by the techniques of indirect mortality estimation, which are used for estimating LE in many developing countries. For most of these populations, detailed data on deaths and the populations at risk are still unavailable or of too bad quality to be useable (Luy 2010a). To produce demographic estimates despite this lack of data, specific estimation techniques - the so-called "indirect methods" - have been developed. These are based on particular survey questions which are included in censuses or special survey projects (for an up-to-date overview of these methods see Moultrie et al. 2013). The dominating indirect technique for the estimation of adult mortality is the so-called "orphanhood method". Its basis is the information whether the survey respondents' mothers and fathers are still alive at the time of interview. The proportion of respondents with mother and father alive is then transformed into a period survival probability from age 25 to age 25 plus the age of respondents. Because the underlying mortality levels and patterns are widely unknown in developing countries, the transformation is based on theoretical population models (see Hill et al. 1983). With the help of model life tables, the best fitting survival function is used as estimated life table for a specific period before the time of the survey. This reference period - i.e. the calendar year to which the life table is assumed to apply - is derived from the age of the respondents and the level of their parents' mortality. Alternative and similarly functioning indirect techniques for estimating adult mortality are based on information about the survival of respondents' siblings and spouses (more details can be found in the above references as well as in Hill et al. 2005; Timæus 1991).

The functionality of these indirect techniques and thus the quality of the resulting estimates depend predominantly on the fit between the assumed theoretical mortality models and the actual mortality patterns. This has been demonstrated for the orphanhood method with data from industrialised countries where the transformation of information about the survival of the respondents' parents into a period life table can be based on empirical data of trends in age-specific mortality (Festy 1995; Luy 2012). The availability of detailed data on mortality trends in developed countries has been used by Luy (2012) to develop a "Modified Orphanhood Method" (MOM) for application in these populations. The MOM has already been deployed by Luy et al. (2011) to estimate LE by education and occupation in Italy - where official population statistics are also limited with respect to socially differentiated mortality - and by Wiedemann (2012) to estimate LE of immigrants in Germany.

The LSM adopts the concept of indirect mortality estimation to transform longitudinal survival data into a period life table. In contrast to these techniques, the ba- 
sic information of the LSM is not the (indirectly surveyed) survival of respondents' relatives but the (directly recorded) survival of the respondents themselves. The basic idea of the LSM can be loosely described as follows: when we have a survey with a mortality follow-up, then we can "ask" the respondents themselves whether they are still alive at the time of the follow-up. Thus, the proportion of respondents who survived until the mortality follow-up can be used for an almost identical transformation into period survivorship as it is done in indirect estimation approaches with the proportions of respondents with relatives alive.

The basis of the LSM is the proportion of individuals in age $x$ at the time of the first survey who survived the time $z$ until the mortality follow-up, denoted by $\hat{S}_{R}(\bar{x}, \bar{x}+\bar{z})$, with the bars indicating the average ages and average observation times of all $x$-year old survey respondents at the time of the first interview. The hat on $\hat{S}_{R}$ indicates that the survival rate is derived directly from the survey data, whereas survival rates without hat - being introduced below - are derived from data for the entire population. The subscript $R$ marks the reference to the survey respondents. $\hat{S}_{R}(\bar{x}, \bar{x}+\bar{z})$ can be calculated by dividing the number of survivors at the time of the mortality follow-up - derived from the difference between the number of respondents at age $x$ at the time of the first survey, $R(x)$, and the number of those who died $D(x)$ - by $R(x)$, thus

$$
\hat{S}_{R}(\bar{x}, \bar{x}+\bar{z})=\frac{R(x)-D(x)}{R(x)} .
$$

In order to maximise our use of the available information for the transformation of these longitudinal survivorships into period survival probabilities, each individual $i$ is used with the precise age $x$ at the time of the first survey and the precise time $z$ until the mortality follow-up (calendar dates transferred into decimals). An expected longitudinal survival $S_{L}(\bar{x}, \bar{x}+\bar{z})$ is estimated for each age from the sum of the individual survival rates from age $x$ to $x+z$ derived from the corresponding survival probabilities $p_{x}$ of cohort life tables for the total population divided by $R(x)$. The expected longitudinal survivals are reconstructed for each survey respondent's precise age $x$ and time $z$ until the mortality follow-up by interpolation from the available cohort life tables (which usually only include survival probabilities for exact ages $x$ ). In formal terms, the estimated expected longitudinal survival for the survey respondents aged $x$ at the time of the first interview until the mortality follow-up results from

$$
S_{L}(\bar{x}, \bar{x}+\bar{z})=\frac{\sum_{i=1}^{R(x)}\left(\frac{p_{x+z}}{p_{x}}\right)}{R(x)} .
$$

In the next step, the corresponding period survivals $S_{P}(\bar{x}, \bar{x}+\bar{z})$ for the reference period $t$ are derived from the period survival probabilities $I_{x^{\prime}}$ which are recon- 
structed - equivalently to the previous step - by interpolation from the available period life tables, thus

$$
S_{P}(\bar{x}, \bar{x}+\bar{z})_{t}=\frac{\sum_{i=1}^{R(x)}\left(\frac{I_{x+z}}{I_{x}}\right)_{t}}{R(x)}
$$

An appropriate reference period $t$ is the mid-year between the times of the first survey and the mortality follow-up. Alternatively, the reference period can also be derived - if available - from the dates of death of the deceased survey respondents. The longitudinal survival rates of the survey respondents $\hat{S}_{R}(\bar{x}, \bar{x}+\bar{z})$ can be transformed into period survival rates from the exact age $x$ to $x+z$ from

$$
\left(\frac{l_{x+z}}{l_{x}}\right)_{t}=\hat{S}_{R}(\bar{x}, \bar{x}+\bar{z}) \cdot w(\bar{x}+\bar{z}, x+z)_{t} \cdot \frac{S_{P}(\bar{x}, \bar{x}+\bar{z})_{t}}{S_{L}(\bar{x}, \bar{x}+\bar{z})},
$$

with $w(\bar{x}+\bar{z}, x+z)_{t}$ being a weighting factor for converting the period survival rate from the age span between $\bar{x}$ and $\bar{x}+\bar{z}$ to the age span from age $x$ to $x+z$ (for exact ages $x$ and survival times $z$ ). These weighting factors can be derived from the period life table for the reference period $t$. The resulting survivorship functions - one for each age $x$ - can be smoothed and extended to the highest ages with the Brass model life table system (Brass 1975), setting the model parameter $\beta=1.0$ and using the reference life table as standard. From the resulting smoothed survival curves, the age-specific probabilities of dying can be derived and weighted averages can be calculated for each age $x$ by taking $R(x)$ into account. This results in a specific age pattern of probabilities of dying $q(x)$ which constitute the final basis for the life table construction.

The LSM can be used to estimate life tables for any sub-population of the underlying survey. The only necessary assumption is that the relationship between cohort and period survival prevalent in the entire population, which is used for the transformation in formula (4), applies equivalently to each subpopulation.

\subsection{Application to the data of the German Life Expectancy Survey (LES)}

Mortality data from surveys with mortality follow-ups are rarely large and complete enough to apply an estimation method such as the LSM without specific adjustments. For our analysis, we used data from the western sample of the German Life Expectancy Survey (LES). The LES is a panel that consists of two waves of interviews, restricted to individuals with German citizenship, and is based on the National Health Survey. The first wave was carried out between 1984 and 1986 and included a representative random sample of the total West German population. In 1998, the German Federal Institute for Population Research (Bundesinstitut für Bevölkerungsforschung, $\mathrm{BiB}$ ) carried out a follow-up survey among the individuals 
interviewed in the 1984/86 National Health Survey. In this second survey, the initial questionnaires were slightly modified - e.g. purely medical details were removed and replaced by questions on general living conditions and family situations - and the number of respondents was restricted to those born between 1914 and 1952 (more details can be found in Gärtner 2001). The LES contains demographic indicators as well as information about economic and social status, social networks, health behaviours, life attitudes and a variety of health indicators.

The western German LES sample includes a total of 4,139 women and 4,335 men. Of those, 304 women ( 7.3 percent) and 653 men ( 15.1 percent) died between the two survey waves. For 1,047 women (25.3 percent) and 903 men (20.8 percent) the survival status by 1998 is unknown. Tests of the quality of the LES mortality data revealed that the reflected survival of the LES sample between 1984 and 1998 is representative for the western German population, regardless of whether individuals with unknown survival status in 1998 are included or not (Luy/Di Giulio 2005; Salzmann/Bohk 2008). As suggested by Luy and Di Giulio (2005) we excluded the individuals with unknown survival status from the analysis. A sensitivity analysis on the basis of the average health statuses of individuals with known and unknown survival statuses at the time of the mortality follow-up indicates that neither the reduced LES sample as a whole nor the small SEP subgroups (which are introduced in more detail below) are health-biased. The differences in average health status between individuals with known and unknown survival statuses are minor in most subpopulations and in no case statistically significant (see Appendix, Tables A1 and A2). Thus, we can assume that the mortality of the SEP subpopulations is also reflected properly in the reduced LES sample.

In the following, we illustrate how we applied the LSM to the LES data. The first step is the calculation of the observed longitudinal survival of the survey respondents. For instance, the LES sample includes 71 women who were 65 years old at the time of the first survey, their average age being 65.4 years, thus $\bar{x}=65.4$. The first wave interviews of these women took place in the year 1985.3 (on average), and the second interviews of those who survived until wave 2 were conducted in the year 1998.4 (on average). Thus, the observed survival time until the mortality follow-up was 13.1 years, hence $\bar{z}=13.1$. During this time, 18 of the women died and 53 survived. Applying these numbers to formula (1) indicates that

$$
\hat{S}_{R}(65.4,78.5)=\frac{53}{71}=0.7465 .
$$

In total, we obtain $70 \hat{S}_{R}(\bar{x}, \bar{x}+\bar{z})$ estimates for women and men and the single ages 35 to 69 , covering the survival rates from age 35.5 to 48.6 until age 69.6 to 82.9 among women, and from age 35.5 to 48.6 until 69.4 to 82.6 among men. For each of these estimates, the expected longitudinal survival is determined by formula (2) on the basis of the German cohort life tables published by the German Statistical Office (Statistisches Bundesamt 2006). As described in section 2.1, the calculation incorporates the observed survival times of each individual of the LES sample with the precise ages at the beginning and at the time of the mortality follow-up, assum- 
ing for the deceased individuals the average time of the second interview as time of mortality follow-up.

When mortality estimation is conducted with survey data such as the LES, the sample sizes can in some cases become so small that not every single age group contains deceased individuals. To overcome this problem, we estimated the survival rates from moving averages of 11 age groups, i.e. estimating the survival rate for age 40 from the average of the ages 35 to 45 , the survival rate for age 41 from the average of the ages 36 to 46 and so on. Figure 1 shows the resulting $\hat{S}_{R}(\bar{x}, \bar{x}+\bar{z})$ values for women and men and every single age (grey arrows) in comparison to the corresponding expected longitudinal survivals derived from the German cohort life tables (bold black lines).

Fig. 1: Observed and expected longitudinal survival rates for the LES sample by single ages (11-year moving averages)

(a) Men

Longitudinal survival rate

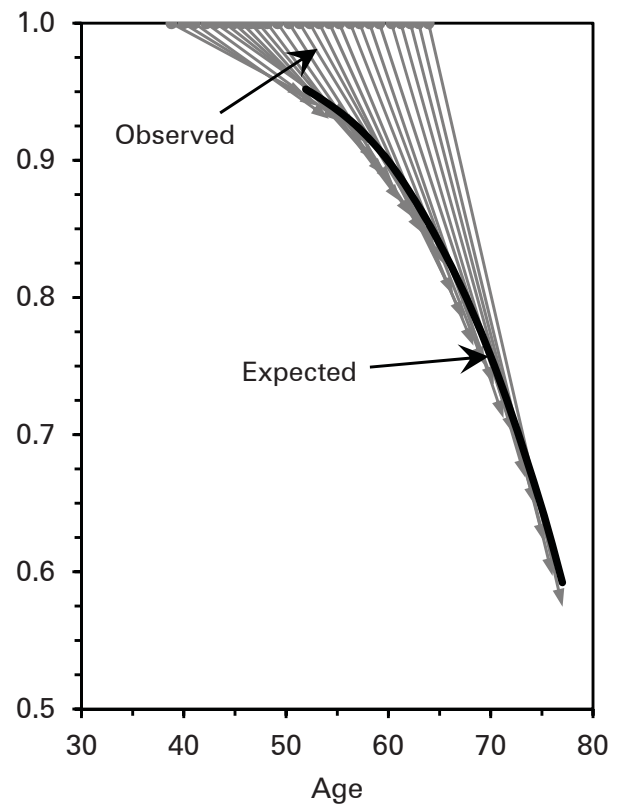

(b) Women

Longitudinal survival rate

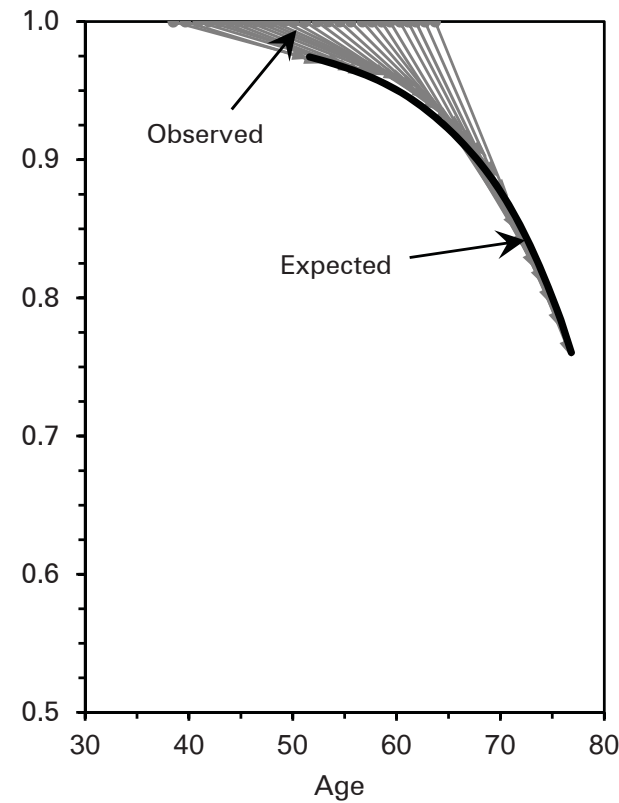

Source: own calculations with LES data

The next steps of the transformation of the proportions of surviving survey respondents into period survivorship estimates are performed as described in the previous section, by applying formulas (3) and (4). We chose the year 1992 as our reference period, as it lies between the average points in time at which the surveys were conducted. The corresponding period survival probabilities were taken from the official period life table 1991/93 for western Germany, published by the German Statistical Office. This life table ends with the open age interval of $90+$ years. 
We extended the life table to age 110 by applying the Kannisto model, which has proven to be the most accurate method for extrapolating mortality at highest ages (Thatcher et al. 1998). After smoothing the single survival functions with the Brass logit life table model, we averaged the resulting probabilities of dying for each single age. We used weighted averages, giving higher weights to the probabilities of dying from survival functions being based on observations from the survey data, and giving lower weights to those that resulted from extrapolation of survival functions derived from observations of younger ages. This was done by weighting the probabilities with the number of survivors of the corresponding survival function.

Figure 2 shows the estimated probabilities of dying, gained from the LES data, for all women and men with the LSM in comparison to the corresponding values of the official German life table 1991/93 for ages 40 to 90 . The figure illustrates the functionality of the method, as the estimates derived from the LES with the LSM are very close to the values from the official German life table for the entire population. The corresponding LE estimates for the LES sample are also close to the official German life table, being slightly lower among men ( 34.5 vs. 35.2 years) and slightly higher among women (41.1 vs. 40.7 years).

We performed the illustrated LSM estimations for each examined SEP subpopulation. We used information from the LES about education, household income and

Fig. 2: Estimated probabilities of dying for ages 40 to 90 with the LSM in comparison to the corresponding values of the official German life table $1991 / 93$

Probability of dying (log. scale)

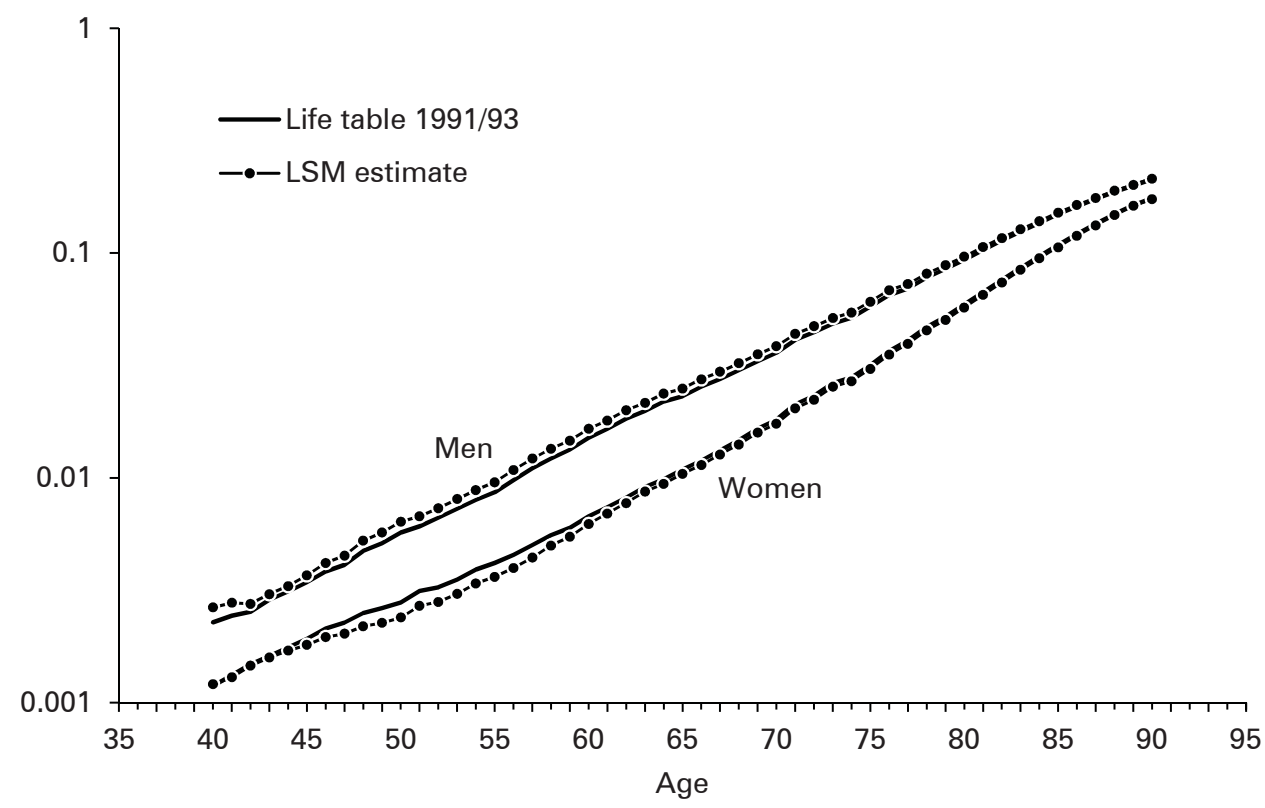

Source: Statistical Office of Germany, own calculations with LES data 
occupation at the time of first interview in 1984/86 as indicators for individuals' SEP. Educational attainment was grouped according to the ISCED-97 scale (United Nations Educational Scientific and Cultural Organization 1996) into the three levels of "low" (ISCED 0-2), "medium" (ISCED 3-4) and "high" (ISCED 5-6). The ISCED combines school and vocational training degrees and is used in most international studies. The monthly net household income was separated into quartiles. The first quartile indicates the lowest income group (less than $895 €$ ) while the fourth quartile indicates the group with the highest income (1,917 $€$ and more).

The current - or, in the case of retirement or unemployment, the last - position on the labour market is defined on the basis of the work status as well as the vocational class. The work status includes four main groups: manual workers, employees, public servants and self-employed workers. Each main group was further subdivided into two or three specific work status subgroups, such as unskilled and skilled workers or employees in simple, qualified and highly qualified tasks. The vocational classes are recorded in the LES according to the German Classification of Professions KIdB-92 (Statistisches Bundesamt 1992). The KIdB-92 provides a hierarchical order of all professions with respect to the industrial segment with the six main classes (i) husbandry, forestry and horticulture, (ii) mining and mineral workers, (iii) production jobs, (iv) technical occupations, (v) service sector, and (vi) other work force. Each of these main classes includes up to three sublevels of specific professions. Because of the case numbers it was only possible to analyse the main classes and the first sublevel. Nonetheless, the main and first level subclasses allow us to isolate specific professions with substantial health risks, such as miners and mineral workers, structural and civil engineers or metalworkers.

In contrast to the more common International Standard Classification of Occupation (International Labour Office 2012), the KIdB-92 does not define the skill level and specification of an individual's profession. Thus, the KIdB-92 does not present differentiations between chief or senior positions on the one hand and workers or clerks on the other in a specific occupational group. For instance, the jobs in the health sector, as a subclass of the service sector, contain physicians as well as nurses. As is to be expected, the number of different occupations depends on gender. The employment rate of women - particularly for the cohorts contained in the LES sample - is notably lower than for males, leading to less variations and smaller case numbers in the female occupation groups.

Descriptive statistics for each of the analysed subpopulations can be found in the Appendix (Tables $\mathrm{A} 3$ and $\mathrm{A} 4$ ), including the number of respondents $R$, the number of deaths $D$, the average age at the time of first survey $\bar{x}$, the average survival time until the mortality follow-up $\bar{z}$, and the entire subsamples' survival rate $\hat{S}_{R}(\bar{x}, \bar{x}+\bar{z})$. We restricted the analysis to subpopulations with at least five observed deaths and estimated 95 percent confidence intervals for LE with the method proposed by Chiang (1984). The required death numbers for each single age were derived from applying the estimated survival functions to the number of individuals of the LES sample belonging to the particular subpopulation. The complete life tables for each subpopulation with the corresponding confidence intervals are available in csv-format as online supplement. 


\section{$3 \quad$ Results}

Table 1 presents an overview of the results for each analysed SEP subpopulation of men, including estimates for the remaining LE at age $40\left(e_{40}\right)$, the probability to survive from age 40 to $65\left({ }_{25} \mathrm{p}_{40}\right)$, and the remaining LE at age $65\left(\mathrm{e}_{65}\right)$. All estimates refer to the period 1991/93. Cases in which the 95 percent confidence interval for $\mathrm{e}_{40}$ respective $\mathrm{e}_{65}$ does not include the corresponding value for the total male LES population are marked with an asterisk. Figure 3 provides an additional visual summary for selected subpopulations by showing the differences in $\mathrm{e}_{40}$ (black bars) and $\mathrm{e}_{65}$ (white bars) to the values of the total male population (Figures $3 \mathrm{c}$ and $3 \mathrm{~d}$ for the work statuses and vocational classes include all main groups and the subgroups with the lowest and highest values of $\mathrm{e}_{40}$ and $\mathrm{e}_{65}$ ).

The results confirm the existence of striking differences in LE among men across all the four analysed SEP indicators (education, household net income, work status and vocational class). For the subpopulations with the highest and lowest LE, the differences to the total population are statistically significant despite the low case numbers in the LES sample (i.e. the 95 percent confidence intervals for these subpopulations do not include the LE value for the total male population). The LE at age 40 by education level varies by 6.3 years, being 32.0 years for low, 34.0 years for medium and 38.3 years for highly educated men. The probability of survival until age 65 differs by 0.145 between men with a high $\left.{ }_{25} p_{40}=0.870\right)$ and men with a low level of education $\left.{ }_{25} \mathrm{p}_{40}=0.725\right)$, i.e. the proportion of 40 -year-old individuals who survive until age 65 is 14.5 percentage points higher for highly educated men than for their counterparts with a low education. At age 65, remaining LE for men still shows significant differences, with a gap of 3.7 years between a high $\left(e_{65}=16.5\right)$ and a low education $\left(\mathrm{e}_{65}=12.8\right)$.

Similar - but slightly smaller - differences can be seen with regard to the net household income quartiles. The LE gap between men belonging to the first $\left(e_{40}=31.1, e_{65}=12.8\right)$ and fourth quartile $\left(e_{40}=36.8, e_{65}=15.6\right)$ is 5.7 years at age 40 and 2.8 years at age 65 . The probabilities to survive from age 40 to age 65 are 0.838 for men in the highest and 0.697 for men in the lowest household income quartile. Figures $3 \mathrm{a}$ and $3 \mathrm{~b}$ reveal that the social gradient in mortality does not only affect the individuals in the lowest and the highest SEP, but applies to all SEP groups: the higher the SEP, the higher the LE.

The social gradient in mortality also becomes apparent when work status is used as indicator for SEP. Among the main work status groups, manual workers exhibit the lowest LE $\left(e_{40}=32.4, e_{65}=13.2\right)$, followed by public servants $\left(e_{40}=35.6\right.$, $\left.e_{65}=14.8\right)$, employees $\left(e_{40}=36.1, e_{65}=15.2\right)$ and self-employed workers $\left(e_{40}=36.6\right.$, $\left.e_{65}=15.3\right)$. Thus, compared to manual workers, the surplus in LE for public servants, employees and self-employed workers is $3.2,3.7$ and 4.2 years at age 40 , and 1.6, 2.0 and 2.1 years at age 65 . The corresponding differences in the probability to survive from age 40 to age 65 are $0.101,0.088$ and 0.080 , respectively. The differences in LE become larger when we consider the work status subgroups. At age 40, the lowest LE can be found for employees in simple tasks $\left(\mathrm{e}_{40}=30.1\right)$ and the highest LE for self-employed farmers $\left(e_{40}=39.6\right)$, yielding an $e_{40}$-difference of 9.5 years. The 
Tab. 1: Life expectancy at ages $40\left(\mathrm{e}_{40}\right)$ and $65\left(\mathrm{e}_{65}\right)$ and the survival probability between ages 40 and $65\left({ }_{25} p_{40}\right)$ by different indicators for SEP, Men

\begin{tabular}{|c|c|c|c|}
\hline SEP indicator / subpopulation & $\mathrm{e}_{40}$ & ${ }_{25} \mathrm{p}_{40}$ & $\mathrm{e}_{65}$ \\
\hline All men & 34.5 & 0.789 & 14.2 \\
\hline \multicolumn{4}{|l|}{ Education according to ISCED-97 ${ }^{1}$} \\
\hline Low (ISCED 1-2) & $32.0^{*}$ & 0.725 & $12.8^{*}$ \\
\hline Medium (ISCED 3-4) & 34.0 & 0.775 & 14.0 \\
\hline High (ISCED 5-6) & $38.3^{*}$ & 0.870 & $16.5^{*}$ \\
\hline \multicolumn{4}{|l|}{ Household net income } \\
\hline $1^{\text {st }}$ quartile (below $\left.€ 895\right)$ & $31.1^{*}$ & 0.697 & $12.8^{*}$ \\
\hline $2^{\text {nd }}$ quartile $(€ 895-1,406)$ & 34.8 & 0.798 & 14.3 \\
\hline $3^{\text {rd }}$ quartile $(€ 1,406-1,917)$ & 35.5 & 0.812 & 14.9 \\
\hline $4^{\text {th }}$ quartile $(€ 1,917$ and more $)$ & $36.8^{*}$ & 0.838 & $15.6^{*}$ \\
\hline \multicolumn{4}{|l|}{ Work status } \\
\hline Manual workers (all) & $32.4^{*}$ & 0.737 & $13.2^{*}$ \\
\hline Unskilled or semi-skilled workers & $30.4^{*}$ & 0.678 & $12.4^{*}$ \\
\hline Skilled workers & 34.2 & 0.787 & 13.8 \\
\hline Master craftsmen, overseers, foremen & 32.7 & 0.740 & 14.0 \\
\hline Employees (all) & $36.1^{*}$ & 0.825 & $15.2^{*}$ \\
\hline Simple tasks & $30.1^{*}$ & 0.659 & 12.5 \\
\hline Qualified tasks & 35.4 & 0.808 & 14.6 \\
\hline Highly qualified tasks & $38.3^{*}$ & 0.869 & $16.6^{*}$ \\
\hline Public servants (all) & 35.6 & 0.817 & 14.8 \\
\hline Simple or medium service & 33.4 & 0.756 & 13.8 \\
\hline Higher or senior service & $37.8^{*}$ & 0.867 & $15.9^{*}$ \\
\hline Self-employed workers (all) & $36.6^{*}$ & 0.838 & 15.3 \\
\hline Entrepreneurs & 35.0 & 0.800 & 14.7 \\
\hline Freelancers & 37.4 & 0.848 & 15.8 \\
\hline Farmers & $39.6^{*}$ & 0.902 & $16.8^{*}$ \\
\hline \multicolumn{4}{|l|}{ Vocational classes according to KIdB-92 ${ }^{2}$} \\
\hline Jobs in (animal) husbandry, forestry, horticulture & 33.1 & 0.749 & 14.2 \\
\hline Miners and mineral workers & 26.2 & 0.541 & 11.5 \\
\hline Production jobs (all) & 33.3 & 0.761 & 13.5 \\
\hline Metal production and metal working & 34.9 & 0.808 & 14.3 \\
\hline Metal constr., mech. engineering and similar & 31.9 & 0.705 & 13.7 \\
\hline Electrical engineering & 33.8 & 0.767 & 13.0 \\
\hline Foodstuffs sector & 33.7 & 0.762 & 13.7 \\
\hline Structural and civil engineering & 30.9 & 0.693 & 13.0 \\
\hline Wood and plastics processing & $39.6^{*}$ & 0.913 & 16.3 \\
\hline Painting, varnishing and similar occupations & 38.2 & 0.864 & 16.6 \\
\hline Unskilled workers without specification & 32.3 & 0.747 & 11.5 \\
\hline
\end{tabular}


Tab. 1: Continuation

\begin{tabular}{llll}
\hline SEP indicator / subpopulation & $\mathrm{e}_{40}$ & ${ }_{25} \mathrm{p}_{40}$ & $\mathrm{e}_{65}$ \\
\hline Technical occupations (all) & $39.4^{*}$ & 0.895 & $16.8^{*}$ \\
Engineering, chemistry, physics, maths & $38.8^{*}$ & 0.871 & $17.1^{*}$ \\
Technicians, technical specialists & $39.5^{*}$ & 0.900 & $16.7^{*}$ \\
Service sector (all) & 35.0 & 0.800 & 14.5 \\
Goods und service marketing & 34.4 & 0.786 & 14.3 \\
Transport industry & $31.9^{*}$ & 0.725 & 13.0 \\
Organisation, administration, clerical jobs & 35.1 & 0.801 & 14.8 \\
Public and private security sector & 34.2 & 0.788 & 13.7 \\
Health sector & 38.8 & 0.864 & 17.0 \\
Social service and education & $40.6^{*}$ & 0.909 & $18.0^{*}$ \\
Other service occupations & 38.2 & 0.874 & 15.9 \\
Other work force & 32.9 & 0.744 & 14.1 \\
\hline
\end{tabular}

* = statistical significant deviation from total LE, $\mathrm{p}<0.05$

${ }^{1}$ ISCED-97 = International Standard Classification of Education

2 KldB-92 = German Classification of Professions

Note: Estimates for the small subgroups of work statuses and vocational classes have to be interpreted with caution. Some of them are based on very small case numbers (see Appendix, Table A3), and the shapes of the estimated period life tables might differ from the longitudinal survival patterns of the corresponding LES subsamples.

Source: own calculations with LES data

probabilities of surviving from age 40 to age 65 are 0.659 and 0.902 respectively, i.e. a difference of 24.3 percentage points. At age 65 , the gap in remaining LE is 4.4 years between self-employed farmers with the highest $\operatorname{LE}\left(\mathrm{e}_{65}=16.8\right)$ and unskilled or semi-skilled manual workers with the lowest LE $\left(\mathrm{e}_{65}=12.4\right)$.

The largest differences in mortality and longevity can be found between the vocational classes. Miners and mineral workers are the main class with the highest mortality. Their LE at age 40 is 26.2 years, and only slightly more than half of them survive until age $\left.65{ }_{25} \mathrm{p}_{40}=0.541\right)$. In contrast, the technical occupations are the main vocational class exhibiting the lowest mortality, with LE at age 40 being 39.4 years and the probability of surviving until age 65 being almost 90 percent $\left({ }_{25} \mathrm{p}_{40}=0.895\right)$. In between are the service sector $\left(\mathrm{e}_{40}=35.0,{ }_{25} \mathrm{p}_{40}=0.800\right)$, production jobs $\left(\mathrm{e}_{40}=33.3,{ }_{25} \mathrm{p}_{40}=0.761\right)$, jobs in (animal) husbandry, forestry and horticulture $\left(\mathrm{e}_{40}=33.1,{ }_{25} \mathrm{p}_{40}=0.749\right)$ and the residual category "other workforce" $\left(e_{40}=32.9,{ }_{25} p_{40}=0.744\right)$. With regard to LE at age 65 , we find the same order of subgroups, with miners and mineral workers exhibiting the lowest $\left(e_{65}=11.5\right)$, and the technical occupations the highest level of LE $\left(e_{65}=16.8\right)$. 
Fig. 3: Deviation of life expectancy at ages 40 and 65 of subpopulations defined by specific SEP indicators from the total population, Men

(a) Education

Difference to total LE

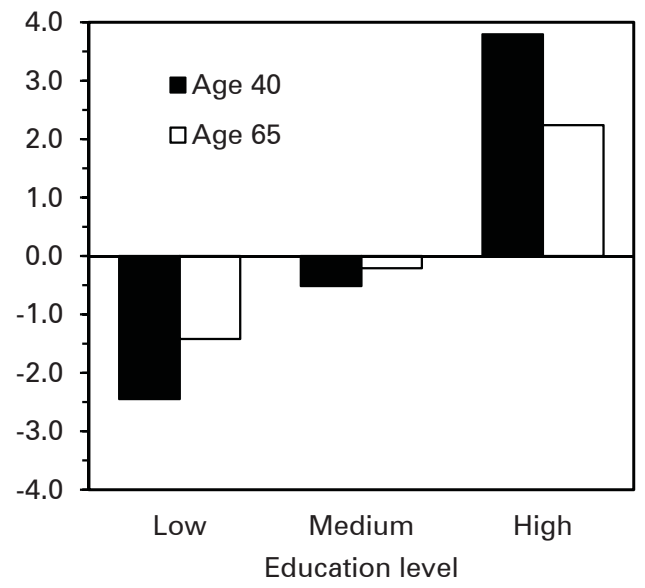

(c) Work status

Difference to total LE

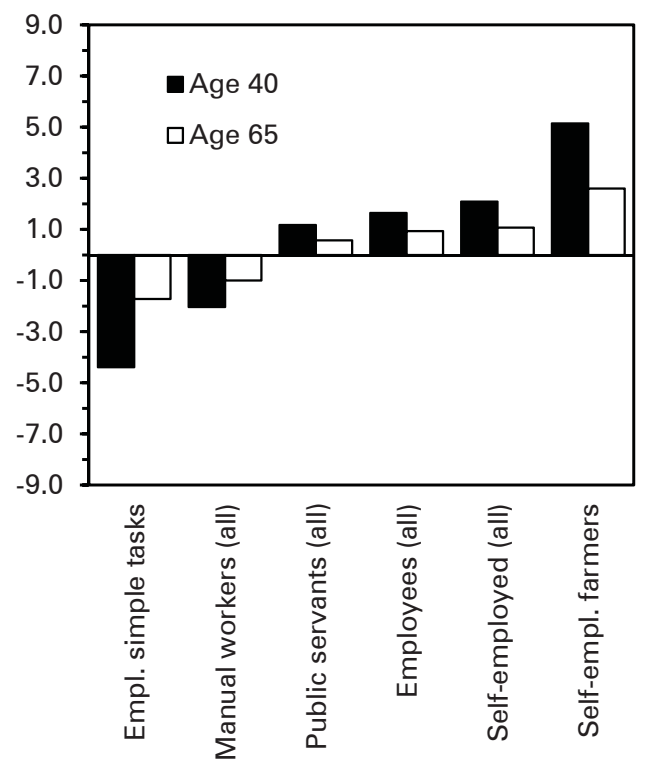

(b) Household net income Difference to total LE

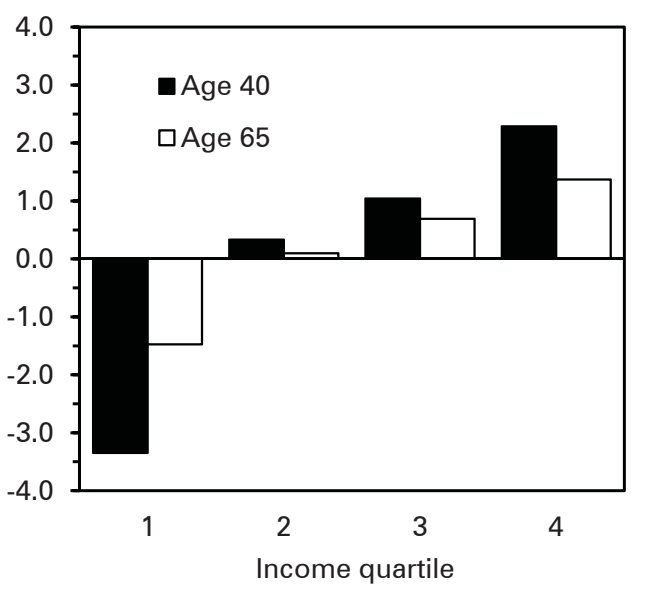

(d) Vocational class

Difference to total LE

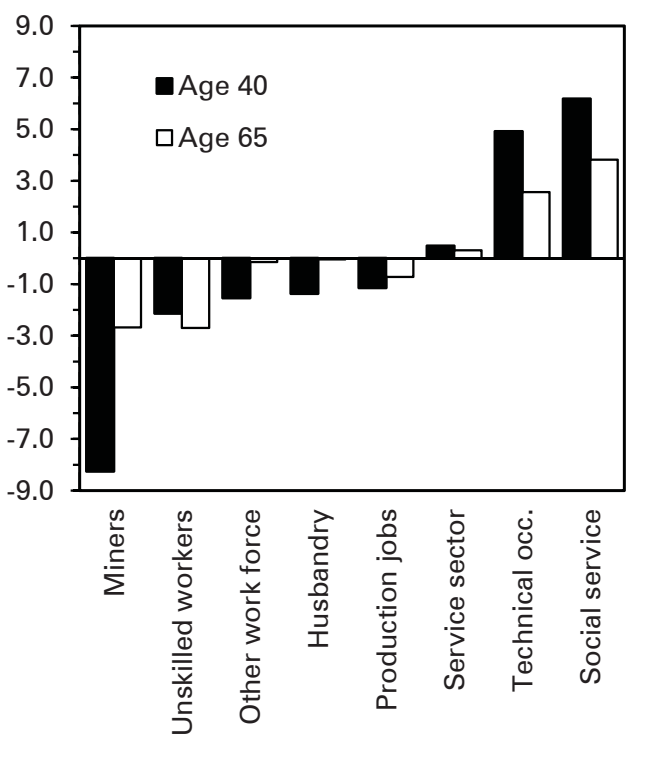

Source: own calculations with LES data 
The differences become even greater when we examine the subclasses. Miners and mineral workers remain the subgroup with the lowest LE at age 40 . This vocational subclass also has the lowest LE at age 65, together with unskilled workers in production jobs, with a remaining LE of 11.5 years. However, compared to the miners and mineral workers, the unskilled workers in production jobs have a lower mortality at younger ages, with $e_{40}$ being 32.3 years and the probability of surviving from age 40 to 65 being almost 75 percent $\left({ }_{25} p_{40}=0.747\right)$. The lowest mortality level of all vocational subclasses can be found among men working in the social service and education sector, including mostly school teachers, but also scientists and social workers $\left(e_{40}=40.6, e_{65}=18.0\right)$. Their advantage in LE compared to the vocational subclasses with the highest mortality levels is 14.4 years at age 40 and 6.5 years at age 65 . Members of the social service and education sector have a 0.909 probability of surviving from age 40 to 65 .

The corresponding results for women are summarised in Table 2 and Figure 4. Compared to men, the differences in LE and survival probabilities between ages 40 and 65 are smaller and in fewer cases statistically significantly different from the total female LES population. To facilitate the comparison of the LE differentials among women and men, we use an identical axis scaling in Figures 3 and 4. With regard to education and household net income, we find the same SEP gradient for women as for men. The difference in LE between women with a high $\left(e_{40}=43.0, e_{65}=20.3\right)$ and a low education $\left(e_{40}=40.7, e_{65}=18.3\right)$ is 2.3 years at age 40 and 2.0 years at age 65. Differently from men, we find a larger LE span among the household net income quartiles than across the three education groups. The differences in LE at ages 40 and 65 between women belonging to the highest $\left(e_{40}=43.4, e_{65}=20.1\right)$ and lowest household income quartiles $\left(e_{40}=39.2, e_{65}=17.5\right)$ are 4.2 and 2.6 years, respectively. The corresponding spans in the probabilities to survive from age 40 to age 65 are 0.020 across the education groups and 0.063 across the household income quartiles.

More interesting differences between women and men can be found with regard to the work statuses. Across the main work status groups, manual workers also show the lowest LE at age 40 among women $\left(e_{40}=40.2\right)$, but the group of employees exhibits only a small advantage of 0.5 years $\left(e_{40}=40.7\right)$. The highest LE at age 40, among the main work status groups, can be found for female public servants $\left(e_{40}=46.7\right)$ with 6.5 years more than manual workers. Self-employed women $\left(e_{40}=43.6\right)$ are placed between employees and public servants, with a 3.4year advantage to the manual workers. The same order holds for LE at age 65 . Compared to the manual workers $\left(e_{65}=17.8\right)$, the surplus of employees $\left(e_{65}=18.3\right)$, self-employed women $\left(e_{65}=20.2\right)$ and public servants $\left(e_{65}=22.9\right)$ is $0.5,2.4$ and 5.1 years, respectively. The highest probability of surviving from age 40 to age 65 can be found among public servants, with ${ }_{25} \mathrm{p}_{40}$ being 0.960 . The lowest survival probability is prevalent among the manual workers $\left.l_{25} p_{40}=0.900\right)$. Employees and self-employed women lie in between with ${ }_{25} \mathrm{p}_{40}$ being 0.902 and 0.944 , respectively. Across the work status subgroups, we find the highest mortality among employees in highly qualified tasks $\left(\mathrm{e}_{40}=38.3, \mathrm{e}_{65}=16.5,{ }_{25} \mathrm{p}_{40}=0.866\right)$ and the lowest mortality among self-employed entrepreneurs $\left(e_{40}=49.4, e_{65}=24.8,{ }_{25} p_{40}=0.986\right)$. The 
Tab. 2: Life expectancy at ages $40\left(\mathrm{e}_{40}\right)$ and $65\left(\mathrm{e}_{65}\right)$ and the survival probability between ages 40 and $65\left(_{25} \mathrm{p}_{40}\right)$ by different indicators for SEP, Women

\begin{tabular}{|c|c|c|c|}
\hline SEP indicator / subpopulation & $\mathrm{e}_{40}$ & ${ }_{25} \mathrm{p}_{40}$ & $\mathrm{e}_{65}$ \\
\hline All women & 41.1 & 0.911 & 18.5 \\
\hline \multicolumn{4}{|l|}{ Education according to ISCED-97' } \\
\hline Low (ISCED 1-2) & 40.7 & 0.903 & 18.3 \\
\hline Medium (ISCED 3-4) & 41.3 & 0.915 & 18.6 \\
\hline High (ISCED 5-6) & 43.0 & 0.923 & 20.3 \\
\hline \multicolumn{4}{|l|}{ Household net income } \\
\hline $1^{\text {st }}$ quartile (below $\left.€ 895\right)$ & $39.2^{*}$ & 0.877 & $17.5^{*}$ \\
\hline $2^{\text {nd }}$ quartile $(€ 895-1,406)$ & 41.0 & 0.910 & 18.5 \\
\hline $3^{\text {rd }}$ quartile $(€ 1,406-1,917)$ & $43.1^{*}$ & 0.929 & $20.2^{*}$ \\
\hline $4^{\text {th }}$ quartile ( $€ 1,917$ and more) & $43.4^{*}$ & 0.940 & $20.1^{*}$ \\
\hline \multicolumn{4}{|l|}{ Work status } \\
\hline Manual workers (all) & 40.2 & 0.900 & 17.8 \\
\hline Unskilled or semi-skilled workers & 39.9 & 0.894 & 17.7 \\
\hline Skilled workers & 42.2 & 0.939 & 18.6 \\
\hline Employees (all) & 40.7 & 0.902 & 18.3 \\
\hline Simple tasks & 39.8 & 0.887 & 17.8 \\
\hline Qualified tasks & 42.2 & 0.923 & 19.3 \\
\hline Highly qualified tasks & 38.3 & 0.866 & 16.5 \\
\hline Public servants (all) & $46.7^{*}$ & 0.960 & $22.9^{*}$ \\
\hline Simple or medium service & 40.2 & 0.864 & 19.1 \\
\hline Self-employed workers (all) & $43.6^{*}$ & 0.944 & $20.2^{*}$ \\
\hline Entrepreneurs & $49.4^{*}$ & 0.986 & $24.8^{*}$ \\
\hline Farmers & 39.1 & 0.867 & 17.8 \\
\hline \multicolumn{4}{|l|}{ Vocational classes according to KIdB-92 ${ }^{2}$} \\
\hline Production jobs (all) & 40.7 & 0.893 & 18.7 \\
\hline Textile sector & 41.5 & 0.901 & 19.4 \\
\hline Foodstuffs sector & 41.6 & 0.898 & 19.6 \\
\hline Unskilled workers without specification & 37.9 & 0.842 & 17.3 \\
\hline Technical occupations (all) & 42.6 & 0.917 & 19.8 \\
\hline Service sector (all) & 41.4 & 0.916 & 18.7 \\
\hline Goods und service marketing & 41.9 & 0.924 & 18.9 \\
\hline Transport industry & 41.0 & 0.914 & 17.9 \\
\hline Organisation, administration, clerical jobs & 41.6 & 0.917 & 18.8 \\
\hline Health sector & 39.3 & 0.875 & 17.7 \\
\hline Social service and education & $45.1^{*}$ & 0.939 & $22.1^{*}$ \\
\hline Other service occupations & 40.5 & 0.904 & 17.9 \\
\hline Other work force & 38.0 & 0.875 & 15.5 \\
\hline
\end{tabular}

* = statistical significant deviation from total LE, $\mathrm{p}<0.05$

1 ISCED-97 = International Standard Classification of Education

2 KldB-92 = German Classification of Professions

Note: Estimates for the small subgroups of work statuses and vocational classes have to be interpreted with caution. Some of them are based on very small case numbers (see Appendix, Table A4), and the shapes of the estimated period life tables might differ from the longitudinal survival patterns of the corresponding LES subsamples.

Source: own calculations with LES data 
Fig. 4: Deviation of life expectancy at ages 40 and 65 of subpopulations defined by specific SEP indicators from the total population, Women

(a) Education

Difference to total LE

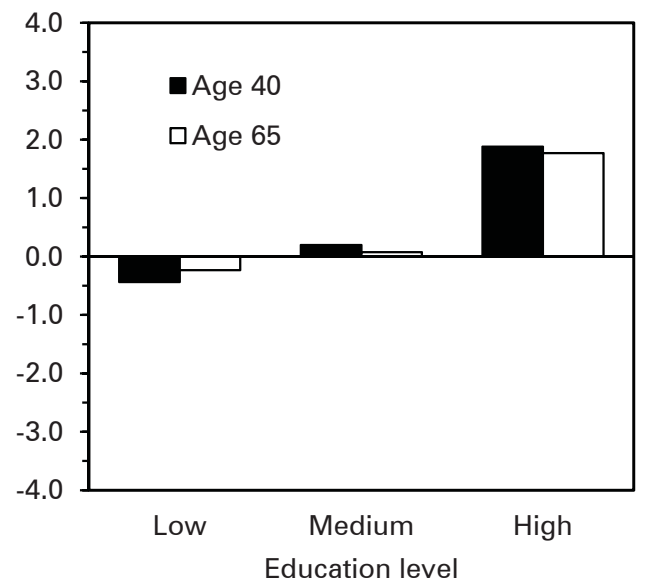

(c) Work status

Difference to total LE

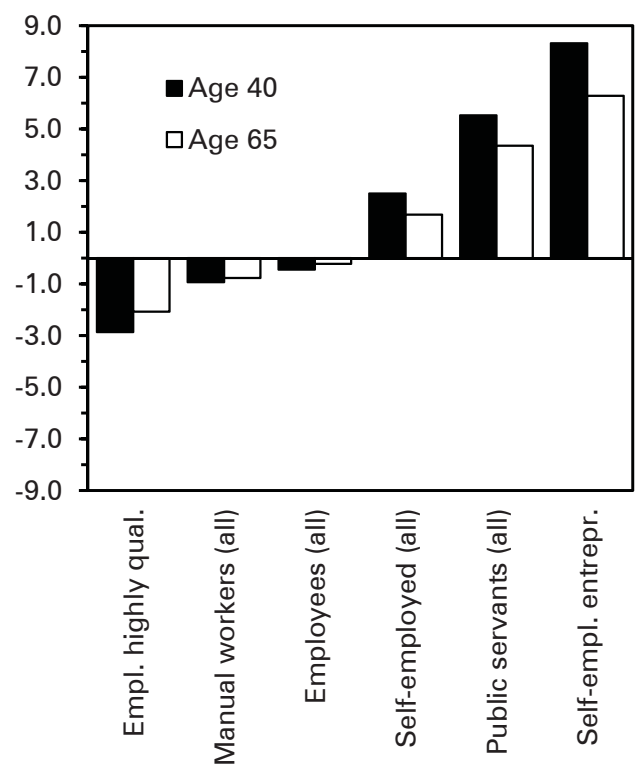

(b) Household net income

Difference to total LE

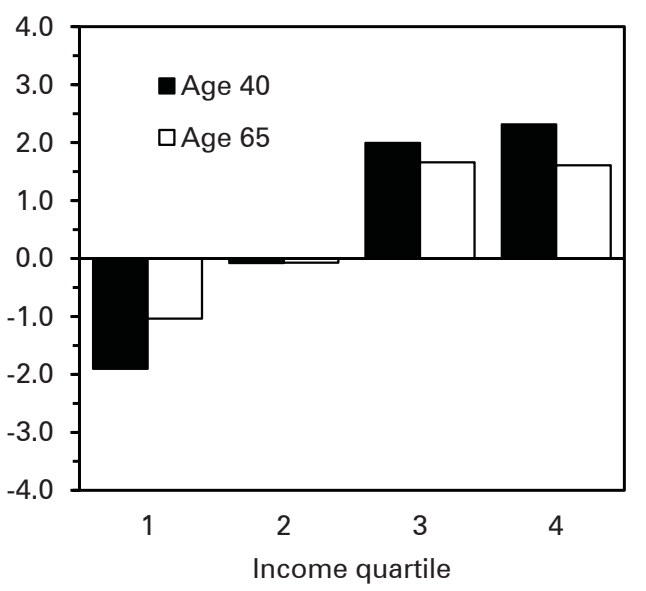

(d) Vocational class

Difference to total LE

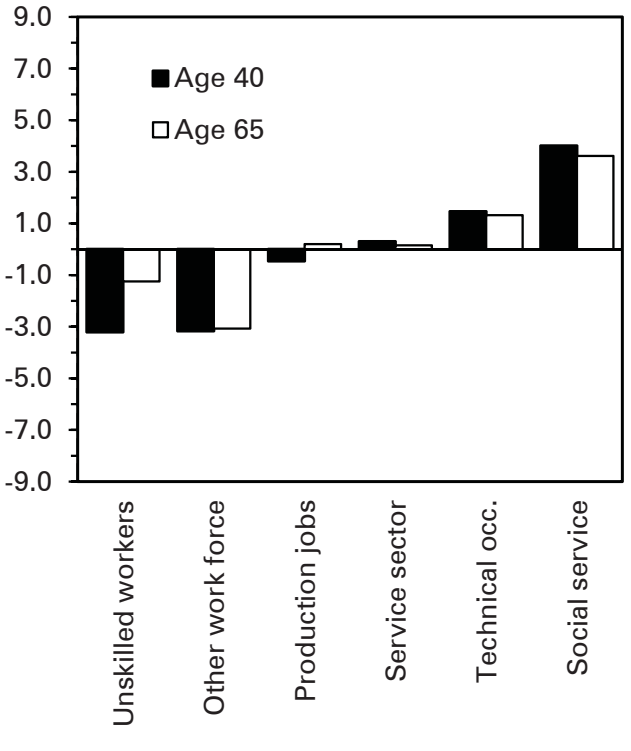

Source: own calculations with LES data 
corresponding differences are 11.1 years in LE at age $40,8.3$ years in LE at age 65, and 0.120 in survival probability between ages 40 and 65 .

Across the main vocational classes with sufficient case numbers for analysis, we find the same order as among men. The technical occupations have the highest $\operatorname{LE}\left(e_{40}=42.6, e_{65}=19.8\right)$, the residual category "other workforce" has the lowest $\left(e_{40}=38.0, e_{65}=15.5\right)$. The LE gaps are 4.6 years at age 40 and 4.3 years at age 65. The corresponding survival probabilities from age 40 to age 65 are 0.917 and 0.875 , respectively. In between these, we find the production jobs $\left(e_{40}=40.7, e_{65}=18.7\right.$, $\left.{ }_{25} p_{40}=0.893\right)$ and the service sector $\left(e_{40}=41.4, e_{65}=18.7,{ }_{25} p_{40}=0.916\right)$. As for male workers, the vocational subclass with the lowest mortality is the social service and education sector. The surplus in LE compared to the vocational subclasses with the highest mortality levels is 7.2 years in $\mathrm{e}_{40}$ (unskilled workers in production jobs and other work force), 6.6 years in $\mathrm{e}_{65}$ (other work force), and 0.097 in the probability of surviving from age 40 to 65 (unskilled workers in production jobs).

Figure 5 depicts the overall range of survival differences by showing the survival functions for the subgroups of men and women with the lowest and highest mortality levels, together with the corresponding total populations. Among men, these are the vocational subclasses "miners and mineral workers" and "social service and education", among women the vocational subclass "unskilled workers in production jobs" and the work status subgroup "self-employed entrepreneurs". The graphs illustrate the substantial survival differences between the displayed popula-

Fig. 5: Survival functions for the male and female subpopulations with lowest and highest life expectancy in comparison to the male and female total populations

(a) Men

Survivors in \%

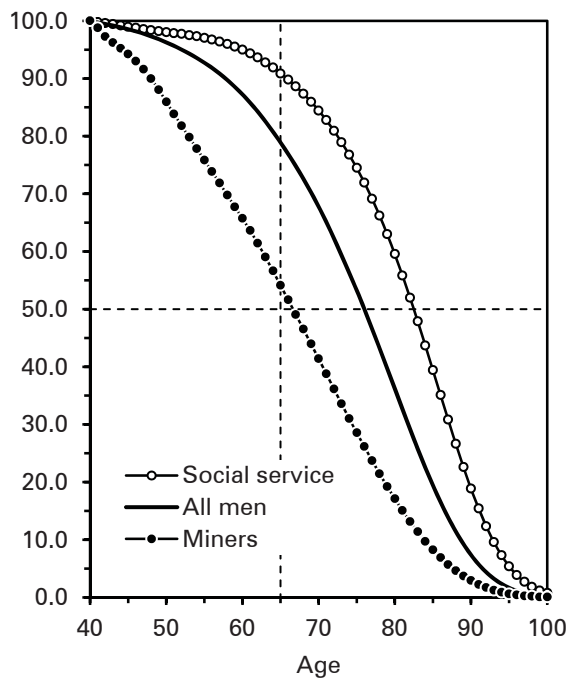

(b) Women

Survivors in \%

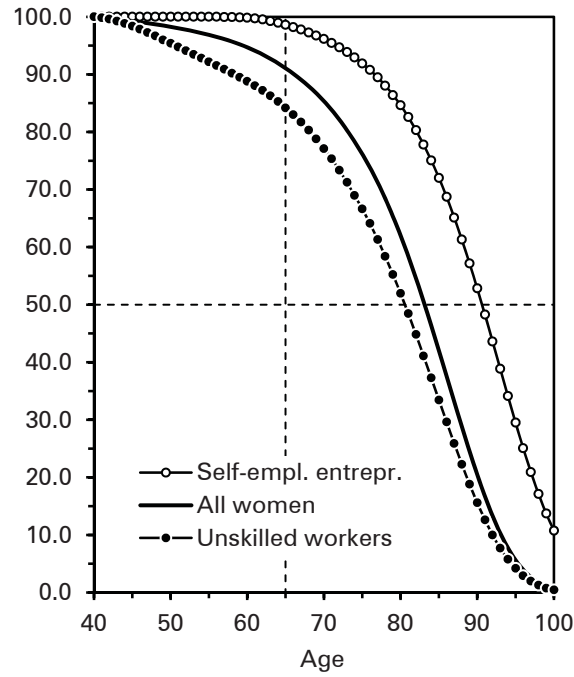

Source: own calculations with LES data 
tion subgroups. For instance, age 65 is reached by 90.9 percent of the 40 -year-old men working in the social service and education sector, but only by 54.1 percent of miners and mineral workers, a difference of 36.8 percentage points (see the crossings of the survival functions with the vertical dotted line in Fig. 3a). Among the displayed female subpopulations, the corresponding percentages are 98.6 for self-employed entrepreneurs and 84.2 for unskilled workers in production jobs, resulting in a difference of 14.4 percentage points. Also, the vertical dotted lines indicating the median of the survival functions reveal the extent of the survival differences. The age to which 50 percent of the initial 40 -year-old individuals survive is 82.5 among the men working in the social service and education sector, but only 66.6 among miners and mineral workers. This leads to a difference in the median survival age of 15.9 years. For women, the corresponding ages are 90.6 for self-employed entrepreneurs and 80.6 for unskilled workers in production jobs, yielding a difference in the median survival age of 10.0 years.

\section{$4 \quad$ Summary and discussion}

\subsection{Method}

The estimation of $L E$ for specific subpopulations and the differentials between them is a common problem for demographers because official population statistics usually do not include the required detailed data on deaths and the population at risk. A few countries - for instance Austria, Belgium, the Netherlands, Switzerland, the United Kingdom and the Scandinavian countries - link their death registries with their census data, population registers or other registers. This enables researchers to construct life tables for specific subpopulations, which can be identified on the basis of the variables covered in the registries or censuses. For most populations, however, such data do not exist, or the information of interest is not included in the registers. Therefore, longitudinal survey data with registration of deceased participants or mortality follow-ups must be used to derive the desired estimates. The case numbers of these data sources are in most cases too small to derive agespecific death rates, even for the larger subpopulations, what prohibits the use of classic life table techniques. Some scholars have employed different approaches to estimate LE on the basis of longitudinal survey data, including proportional hazards models (Li et al. 2014; Reuser et al. 2008; Reuser et al. 2009; Reuser et al. 2011), Bayesian Markov chain Monte Carlo methods (Lynch/Brown 2005), multi-state Markov models (Majer et al. 2011; Matthews et al. 2009), hidden Markov models (Van Den Hout et al. 2009) and the so-called "population attributable fraction" PAF (Preston/Stokes 2011). These approaches combine sophisticated statistical methods with more classic (life table) techniques, resulting in particular statistical properties and data requirements.

In this paper, we developed an alternative but comparatively simple demographic approach for deriving life tables from survey data with a mortality follow-up. We refer to the method as the "Longitudinal Survival Method" (LSM) because it is based 
on longitudinal survival experiences of survey respondents, which are then transformed into a period life table. The transformation procedure of the LSM is basically a direct adoption of the transformation formula of the indirect Modified Orphanhood Method developed by Luy (2012). The differences are (i) that the observed life spans of respondents between the time of the survey and the time of the mortality follow-up can be used with their exact ages, times and lengths, (ii) that the transformation of the survival rates to a default age is not necessary, and (iii) that the reference period for the life table must not be estimated to a time some years before the survey, but can be determined directly to a time between the survey and the mortality follow-up.

The applicability of the LSM is not restricted to the LES data used in this study. The method can be applied to all surveys with a mortality follow-up, such as SOEP, MONICA/KORA or SHARE. The LSM requires only three kinds of information for each age group $x$ of the survey population (with $x$ including single ages from $x$ to $x+1$ or, if necessary, broader age intervals e.g. from $x$ to $x+5$ ) and one assumption:

- The observed longitudinal survival of the survey respondents $\hat{S}_{R}(\bar{x}, \bar{x}+\bar{z})$, i.e. the proportion of individuals aged $x$ at the time of the survey who survived until age $x+z$ at the time of mortality follow-up,

- the expected longitudinal survival of these survey respondents from age $\bar{x}$ to $\bar{x}+\bar{z}$, derived from cohort life tables,

- the corresponding period survival for the same age interval $\bar{x}$ to $\bar{x}+\bar{z}$, derived from the reference period life table, and,

- the assumption that the relationship between cohort and period survival prevalent in the entire population applies equivalently to each subpopulation.

The specific strengths of the LSM include the low demand on data (e.g. no information on the date of deaths and the age at which they occur is necessary, no specific statistical distributions of deaths need to be assumed), its simple applicability, and the estimation of a set of age-specific probabilities of dying. Consequently, the LSM is not based on the assumption of constant relative risks, but yields age-specific mortality patterns for every subpopulation. The different age patterns in the estimates become apparent from the varying orders of the subpopulations' mortality levels according to the used indicators $\mathrm{e}_{40^{\prime}{ }_{25}} \mathrm{p}_{40}$ and $\mathrm{e}_{65^{\prime}}$ e.g. across the vocational subclasses among men. Another strength of the LSM is that it includes a strong longitudinal component, which makes the estimated differences in period LE between subpopulations less susceptible to distortions caused by period tempo effects (see Luy 2010b). Moreover, when a constancy of the subpopulations' age patterns of mortality and relative differences to the total population can be assumed, the LSM can also be used to produce estimates for other periods by varying the reference life table for the transformation. This can be particularly valuable when the life table for a specific subpopulation produced with the LSM is to be employed for estimating Healthy LE with the basic health information stemming from data for a different period. Finally, the LSM can be used to estimate life tables for any subpopulation 
that can be identified in the underlying data, even when the case numbers are extremely low.

\subsection{Results}

Lifetime inequalities by SEP are an important topic not only for mortality researchers, but also for policy-makers, physicians, public health workers and the general population. Several German books have been dedicated to this subject, with (translated) titles such as "If you are poor, you have to die earlier" (Oppolzer 1986), "Social inequality before death" (Ritz 1992; Spree 1981) or "Must poor people die earlier?" (Helmert et al. 2000). Mortality differences by occupation already sparked interest in the $19^{\text {th }}$ and early $20^{\text {th }}$ centuries (Prinzing 1931; Westergaard 1882). However, these publications only included relative risks for specific subgroups defined by occupation or work status, as also the most recent studies on this topic do (Helmert 2000; Linke 1990). As already described in the introduction, the situation is similar with regard to the other indicators of SEP, and no comprehensive overview of the variation of LE by SEP in the German population exists. The central aim of this paper was therefore to bridge this gap of knowledge by producing corresponding estimates for the SEP dimensions of education, income and occupation. We found clear evidence for social disparities in mortality for all SEP dimensions that we considered. In the following, we summarise the estimated ranges of longevity among the analysed SEP indicators, i.e. the differences between the subgroups with the highest and lowest mortality levels.

According to our estimations for the period 1991/93, based on data of the German LES, LE at age 40 for men ranges by 6.3 years between individuals with a low and a high education, 5.7 years between the lowest and highest household income quartiles, 4.2 years across the main work statuses, and 13.2 years across the main vocational classes. The maximum difference across all analysed male SEP subpopulations is 14.4 years between miners and men working in the social service sector. The proportion of those who reach the classic pension age of 65 years also varies considerably. The spans in percentage points are 14.5 with regard to the education level, 14.1 with regard to household income, 10.1 with regard to the main work status, and 35.4 with regard to the main vocational class. The difference between the subpopulations with the highest and lowest survival probabilities until age 65 is 36.8 percentage points, referring again to miners and men working in the social service sector. Significant differences are even prevalent in the remaining LE at this classic pension age. The ranges in LE at age 65 are 3.7 years for education, 2.8 years for household income, 2.1 years for the main work status, and 5.3 years for the main vocational class. The maximum range in LE at age 65 across all SEP subgroups is 6.5 years between miners and unskilled workers in production jobs on the one hand, and the social service sector on the other.

The corresponding differences among women are smaller, but nonetheless notable. At age 40, LE varies 2.3 years by education level, 4.2 years by household income, 6.5 years by main work status, and 4.6 years by main vocational class. The maximum difference across all analysed female SEP subpopulations is 11.5 years, 
between self-employed entrepreneurs and unskilled workers in production jobs. Due to the generally lower mortality of women in middle ages, the differences in survival until age 65 are less distinct than among men. The proportions of 40 -yearold women reaching age 65 vary by 2.0 percentage points by education, 6.3 by household income, 6.0 by main work status, and 4.2 by main vocational class. The largest difference between the two mentioned subgroups with minimum and maximum mortality levels is 14.4 percentage points. As another consequence of the relatively low female mortality between ages 40 and 65 , the variations in LE at age 65 do not differ considerably from those at age 40 . With regard to education, LE at age 65 varies by 2.0 years, 2.6 years by household income, 5.1 years by main work status, and 4.3 years by main vocational class. The maximum difference in LE at age 65 across all analysed female SEP subpopulations is 9.3 years between the selfemployed entrepreneurs and the main vocational class "other work force".

We are confident that these results are reliable - at least for the main SEP subgroups - for four reasons:

- the LES data is representative for the total population of western Germany,

- the mortality follow-up of the LES is representative for the total population of western Germany (and our sensitivity analysis suggests that this is likely to also hold true for the LES subpopulations),

- subgroup-specific age patterns of mortality are taken into account, and

- our estimates for LE differentials by education level are similar to corresponding data for the neighbouring countries.

The last point is an especially strong indicator of the results' validity. Calculations for Austria on the basis of Austrian census data with one-year mortality followups published by Statistics Austria provide differences in LE (at age 35) between the same ISCED levels of high and low education of 6.1 years among men and 3.3 years among women, averaged for the years 1981-2001 (Klotz/Asamer 2014). Corresponding estimates for the German-speaking part of Switzerland on the basis of the Swiss National Cohort (a linkage of the 1990 census with death certificate data registered between 1990 and 1997) reveal a difference in LE at age 40 of 6.3 years among men and 3.3 years among women (Spoerri et al. 2006). Thus, our estimates for the German population provide an almost identical education-specific difference in LE among men and a gap approximately one year smaller among women.

Similar LE differentials for education among men in the period between 1980 and 2000 can be found, for instance, in the Czech Republic (Shkolnikov et al. 2006), Finland (Shkolnikov et al. 2006; Valkonen et al. 1993; Valkonen et al. 1997) and among the white US population (Crimmins/Saito 2001; Meara et al. 2008). Slightly smaller differences (of about five years) are reported for Belgium (Deboosere et al. 2009), Denmark (Brønnum-Hansen/Baadsgaard 2012) and Lithuania (Kalediene/ Petrauskiene 2000). Considerably larger differentials are prevalent in Russia and Estonia, with a LE difference at young adulthood of more than ten years (Shkolnikov et al. 2006). In general, the same regional differences can be found among the female populations. According to our estimates, however, German women are closer to 
the populations with smaller education-specific differences in LE, such as Denmark and Lithuania, whereas the female Belgian population is - according to the estimations of Deboosere et al. (2009) - closer to the populations with medium-sized differentials (Austria, Czech Republic, Finland, the white US population, Switzerland). Also among women, Russia and Estonia exhibit significantly larger inequalities in LE by education level. Our results for income and occupation are in line with findings for other populations as well, for instance with regard to the order of professions' or work status groups' LE levels and the generally larger differentials among men (see e.g. Brønnum-Hansen 2000; Burström et al. 2005; Hattersley 1999; Valkonen et al. 1993). Nonetheless, the estimates for subclasses have to be interpreted with caution. Some of them are based on very small case numbers. Although the estimated LE values reflect the observed average survival time of the LES subsamples, it can happen that the shape of the estimated period life table differs from the longitudinal survival pattern. This holds true, for instance, for the male workers in wood and plastics processing and in painting, varnishing and similar occupations.

Our results for the German population imply that the variations in survival and longevity are much larger with respect to occupation than with respect to education and household income. The spans are more than double among men and approximately tripled among women. This is due to the fact that the subpopulations defined by specific occupations are more selected than those defined by education and income. When assessing these differences from an analytical point of view, it is also important to note that our estimates are based on empirical life tables - thus reflecting the actual mortality of the survey sample - and not on theoretical ones. The former can include a 100 percent survival rate for some ages when no case of death is observed, while a theoretical life table never features a zero percent probability of dying. Among the subpopulations analysed in our study, this is the case among female self-employed entrepreneurs between ages 40 and 56 , for instance (see Fig. 5b). Nonetheless, the specifics of the resulting survival curve are not as unrealistic as they might seem at first glance. The survivorship function tells us that almost all (98.6 percent) female self-employed entrepreneurs reach age 65 , and that approximately one in ten (10.8 percent) reaches age 100 . Although this survival curve might look exceptional, these figures are not totally impossible.

Another fact to keep in mind is that the presented estimates refer to the early 1990s, and are thus not fully reflective of current developments. However, changes in mortality - especially the relative differences between subpopulations - do not occur very suddenly. This is confirmed by the trends of LE by education level in Austria from 1981 to 2011, where only minor variations took place over time, with the tendency of a slight increase among men and a small decrease among women (Klotz/Asamer 2014). Unger and Schulze (2013) draw a similar picture for the German population in their analysis of education-specific differentials in LE, which did not change between 1989 and 2009 for either sex. Thus, it is likely that the currently prevalent SEP-specific differences in LE among German women and men are close to those presented in this paper.

Finally, it is important to note that this paper was neither intended to analyse the causal mechanisms behind the SEP-specific differences in LE, nor did we aim 
at contributing to the question of which dimension of SEP affects the mortality differentials among the others. Obviously, the different dimensions of SEP are interrelated, but they still have independent effects on mortality (Geyer/Peter 2000). The network of interrelations and causal factors is very complex (see e.g. Schneider 2008; Spijker 2004) and it is possible that the so-called "status syndrome" is only driven by the factors education, income and occupation to a minor extent, but is instead rooted in an overarching mechanism determined by socially-produced hierarchical differences in individuals' autonomy and opportunities for social participation (Marmot 2004). All these questions are still unanswered, and more research is necessary to provide decisive knowledge for developing appropriate strategies for reducing the existing inequalities in LE.

\section{Conclusions}

The LSM provides improved estimates for differentials in LE of subgroups on the basis of survey data with a mortality follow-up. The particular strength of the LSM is the incorporation of age-specific mortality patterns for each subpopulation. The only necessary assumption is that the relationship between cohort and period survival prevalent in the entire population applies equivalently to each subpopulation. Application of the LSM can be extended to estimate cohort life tables as well as multi-state life tables, and it enables researchers to produce estimates even for subpopulations with extremely low case numbers. However, the quality of the data must always be taken into account. If the mortality follow-up is not representative of the population's mortality, no valid estimates can be derived with the LSM (or any other method). Thus, our assessment is in line with Charafeddine et al. (2014), who concluded in their comparative analysis of Healthy LE estimated with Belgium's census and survey data including a mortality follow-up that the latter is a useful and valid data source in the absence of population-wide data when it is of good quality.

This paper illustrates the variation of LE in Germany by SEP. No information about causality can be extracted from these results, and it has to be kept in mind that the estimates are derived in a cross-sectional setting which does not necessarily reflect the factual longitudinal survival. Nonetheless, the results of this study are useful for all researchers, policy-makers and other parties interested in the extent of differences in lifetime by SEP across the German population. In particular, the presented figures provide an interesting subject of discussion for the ongoing debate about the implementation of an increasing pension age, which is considered to be necessary by many scholars in order to reduce the consequences of the demographic change (for a special focus on the German population see e.g. Birg 2001; Schimany 2003; Schmid et al. 2000). Moreover, the results presented in this study provide doctors, scientists and public health workers with insights into the most disadvantaged SEP subpopulations and the potential extent of their disadvantages in both longevity and mortality. 


\section{Acknowledgements}

This research was supported by the European Research Council, within the European Community's Seventh Framework Programme (FP7/2007-2013), ERC Grant Agreement No. 262663 (HEMOX) and ERC Grant Agreement No. 323947 (Re-Ageing). We thank Karla Gärtner (German Federal Institute for Population Research, BiB) for providing us with the LES codes for the specific occupations which are not included in the publically available data set.

\section{Author contributions}

ML developed the idea of the study as well as the method and wrote most parts of the text. CWS helped in refining the method, performed the analyses and contributed to the text. AW contributed to this study by collecting literature on mortality differences by SEP in Germany and giving inputs to the text. JS performed a systematic review of the existing methods for estimating mortality from longitudinal survey data and commented on all parts of the paper.

\section{References}

Birg, Herwig 2001: Die demographische Zeitenwende. Der Bevölkerungsrückgang in Deutschland und Europa. München: Beck.

Brass, William 1975: Methods for estimating fertility and mortality from limited and defective data. Chapel Hill: University of North Carolina.

Brønnum-Hansen, Henrik 2000: Socioeconomic differences in health expectancy in Denmark. In: Scandinavian Journal of Public Health 28,3: 194-199 [doi: 10.1177/14034948000280030801].

Brønnum-Hansen, Henrik; Baadsgaard, Mikkel 2012: Widening social inequality in life expectancy in Denmark. A register-based study on social composition and mortality trends for the Danish population. In: BMC Public Health 12,1: 994 [doi: 10.1186/14712458-12-994].

Burström, Kristina; Johannesson, Magnus; Diderichsen, Finn 2005: Increasing socioeconomic inequalities in life expectancy and QALYs in Sweden 1980-1997. In: Health Economics 14,8: 831-850 [doi: 10.1002/hec.977].

Charafeddine, Rana et al. 2014: Using mortality follow-up of surveys to estimate social inequalities in healthy life years. In: Population Health Metrics 12,1: 13 [doi: 10.1186/1478-7954-12-13].

Chiang, Chin Long 1984: The life table and its applications. Malabar, Florida: Krieger.

Corsini, Veronica 2010: Highly educated men and women likely to live longer. Life expectancy by educational attainment. Statistics in focus 24/2010. Brussels: Eurostat.

Crimmins, Eileen M.; Saito, Yasuhiko 2001: Trends in healthy life expectancy in the United States, 1970-1990: gender, racial, and educational differences. In: Social Science \& Medicine 52,11: 1629-1641 [doi: 10.1016/S0277-9536(00)00273-2]. 
Deboosere, Patrick; Gadeyne, Sylvie; Van Oyen, Herman 2009: The 1991-2004 evolution in life expectancy by educational level in Belgium based on linked census and population register data. In: European Journal of Population 25,2: 175-196 [doi: 10.1007/ s10680-008-9167-5].

Doblhammer, Gabriele; Muth, Elena; Kruse, Anne 2008: Lebenserwartung in Deutschland: Trends, Prognose, Risikofaktoren und der Einfluss ausgewählter Medizininnovationen. Abschlussbericht für den Verband Forschender Arzneimittelhersteller e.V. Rostock: Rostocker Zentrum zur Erforschung des Demografischen Wandels.

Festy, Patrick 1995: Adult mortality and proportions orphaned in Austria in 1991. In: Population: An English Selection 7: 232-238.

Gärtner, Karla 2001: Lebensstile und ihr Einfluss auf Gesundheit und Lebenserwartung. Der Lebenserwartungssurvey des BiB. Materialien zur Bevölkerungswissenschaft 102a. Wiesbaden: Bundesinstitut für Bevölkerungsforschung.

Geyer, Siegfried; Peter, Richard 2000: Income, occupational position, qualification and health inequalities - competing risks? (Comparing indicators of social status). In: Journal of Epidemiology and Community Health 54,4: 299-305 [doi: 10.1136/jech.54.4.299].

Hatters/ey, Lin 1999: Trends in life expectancy by social class - an update. In: Health Statistics Quarterly 2, Summer: 16-24.

Helmert, Uwe 2000: Der Einfluß von Beruf und Familienstand auf die Frühsterblichkeit von männlichen Krankenversicherten. Eine Längsschnittanalyse von Routinedaten der Gmünder Ersatzkasse von 1989 bis 1997. In: Helmert, Uwe et al. (Eds.): Müssen Arme früher sterben? Soziale Ungleichheit und Gesundheit in Deutschland. Weinheim, München: Juventa: 243-268.

Helmert, Uwe et al. 2000: Müssen Arme früher sterben? Soziale Ungleichheit und Gesundheit in Deutschland. Weinheim, München: Juventa.

Hill, Kenneth; Choi, Yoonjoung; Timæus, Ian M. 2005: Unconventional approaches to mortality estimation. In: Demographic Research 13,12: 281-300 [doi: 10.4054/DemRes.2005.13.12].

Hill, Kenneth; Zlotnik, Hania; Trussell, James 1983: Manual X. Indirect techniques for demographic estimation. Population Studies 81. New York: United Nations.

International Labour Office 2012: International Standard Classification of Occupations ISCO-8. Vol. 1: Structure, group definitions and corresponding tables. Geneva: International Labour Office.

Kalediene, Ramune; Petrauskiene, Jadvyga 2000: Inequalities in life expectancy in Lithuania by level of education. In: Scandinavian Journal of Public Health 28,1: 4-9 [doi: $10.1177 / 140349480002800103]$.

Kibele, Eva U. B.; Jasilionis, Domantas; Shkolnikov, Vladimir M. 2013: Widening socioeconomic differences in mortality among men aged 65 years and older in Germany. In: Journal of Epidemiology and Community Health 67,5: 453-457 [doi: 10.1136/jech2012-201761].

Klein, Thomas 1996: Mortalität in Deutschland - Aktuelle Entwicklungen und soziale Unterschiede. In: Zapf, Wolfgang; Schupp, Jürgen; Habich, Roland (Eds.): Lebenslagen im Wandel: Sozialberichterstattung im Längsschnitt. Frankfurt/New York: Campus: 366-377.

Klein, Thomas 1999: Soziale Determinanten der aktiven Lebenserwartung. In: Zeitschrift für Soziologie 28,6: 448-464. 
Klein, Thomas; Schneider, Sven; Löwel, Hannelore 2001: Bildung und Mortalität. Die Bedeutung gesundheitsrelevanter Aspekte des Lebensstils. In: Zeitschrift für Soziologie 30,5: 385-400.

Klotz, Johannes; Asamer, Eva-Maria 2014: Bildungsspezifische Sterbetafeln 2006/2007 sowie 2011/2012. In: Statistische Nachrichten 2014,3: 209-214.

Kunst, Anton 1997: Cross-national comparisons of socio-economic differences in mortality. Rotterdam: Department of Public Health, Erasmus University.

Lampert, Thomas; Kroll, Lars Eric 2014: Soziale Unterschiede in der Mortalität und Lebenserwartung. In: GBE Kompakt 5,2: 1-13.

Lampert, Thomas; Kroll, Lars Eric; Dunkelberg, Annalena 2007: Soziale Ungleichheit der Lebenserwartung in Deutschland. In: Aus Politik und Zeitgeschichte 42: 11-18.

Lampert, Thomas; Kroll, Lars Erik 2006: Einkommensdifferenzen in der Gesundheit und Lebenserwartung - Quer-und Längsschnittbefunde des Sozio-oekonomischen Panels (SOEP). In: Das Gesundheitswesen 68,4: 219-230 [doi: 10.1055/s-2006-926638].

Li, Kuanrong; Husing, Anika; Kaaks, Rudolf 2014: Lifestyle risk factors and residual life expectancy at age 40: a German cohort study. In: BMC Medicine 12,1: 59 [doi: 10.1186/1741-7015-12-59].

Linke, Wilfried 1990: Differentielle Sterblichkeit nach Berufen - Eine Auswertung der Beschäftigtenstatistiken 1984 und 1985. In: Zeitschrift für Bevölkerungswissenschaft 16,1: 29-51.

Luy, Marc 2006: Differentielle Sterblichkeit: die ungleiche Verteilung der Lebenserwartung in Deutschland. In: Sozialverband VdK. Bayern (Ed.): Soziale Verunsicherung ohne Ende? Das politische System setzt die Bürger auch weiter unter Druck. München: VdK-Dimetria: 61-82.

Luy, Marc 2010a: A classification of the nature of mortality data underlying the estimates for the 2004 and 2006 United Nations' World Population Prospects. In: Comparative Population Studies - Zeitschrift für Bevölkerungswissenschaft 35,2: 315-334 [doi: 10.4232/10.CPoS-2010-08en].

Luy, Marc 2010b: Tempo effects and their relevance in demographic analysis. In: Comparative Population Studies - Zeitschrift für Bevölkerungswissenschaft 35,3: 415-446 [doi: 10.4232/10.CPoS-2010-11en].

Luy, Marc 2012: Estimating mortality differences in developed countries from survey information on maternal and paternal orphanhood. In: Demography 49,2: 607-627 [doi: 10.1007/s13524-012-0101-4].

Luy, Marc; Di Giulio, Paola 2005: Der Einfluss von Verhaltensweisen und Lebensstilen auf die Mortalitätsdifferenzen der Geschlechter. In: Gärtner, Karla; Grünheid, Evelyn; Luy, Marc (Eds.): Lebensstile, Lebensphasen, Lebensqualität. Interdisziplinäre Analysen von Gesundheit und Sterblichkeit aus dem Lebenserwartungssurvey des BiB. Schriftenreihe des Bundesinstituts für Bevölkerungsforschung 36. Wiesbaden: VS Verlag für Sozialwissenschaften: 365-392.

Luy, Marc; Di Giulio, Paola; Caselli, Graziella 2011: Differences in life expectancy by education and occupation in Italy, 1980-94: indirect estimates from maternal and paternal orphanhood. In: Population Studies 65,2: 137-155 [doi: 10.1080/00324728.2011.568192].

Lynch, Scott M.; Brown, J. Scott 2005: A new approach to estimating life tables with covariates and constructing interval estimates of life table quantities. In: Sociological Methodology 35,1: 177-225 [doi: 10.1111/j.0081-1750.2006.00168.x].

Mackenbach, Johan P. et al. 1997: Socioeconomic inequalities in morbidity and mortality in western Europe. In: The Lancet 349,9066: 1655-1659. 
Majer, Istvan M. et al. 2011: Socioeconomic inequalities in life and health expectancies around official retirement age in 10 Western-European countries. In: Journal of Epidemiology and Community Health 65,11: 972-979 [doi: 10.1136/jech.2010.111492].

Marmot, Michael 2004: The status syndrome. How social standing affects our health and longevity. London: Bloomsbury.

Matthews, Fiona E. et al. 2009: Education differences in life expectancy with cognitive impairment. In: The Journals of Gerontology Series A: Biological Sciences and Medical Sciences 64A,1: 125-131 [doi: 10.1093/gerona/gln003].

Meara, Ellen R.; Richards, Seth; Cutler, David M. 2008: The gap gets bigger: changes in mortality and life expectancy, by education, 1981-2000. In: Health Affairs 27,2: 350360 [doi: 10.1377/hlthaff.27.2.350].

Moultrie, Tom et al. 2013: Tools for demographic estimation. Paris: IUSSP.

Oppolzer, Alfred 1986: Wenn du arm bist, musst du früh sterben. Hamburg: VSA.

Perna, Laura et al. 2010: Socio-economic differences in life expectancy among persons with diabetes mellitus or myocardial infarction: results from the German MONICA/ KORA study. In: BMC Public Health 10: 135 [doi: 10.1186/1471-2458-10-135].

Preston, Samuel H.; Stokes, Andrew 2011: Contribution of obesity to international differences in life expectancy. In: American Journal of Public Health 101,11: 2137-2143 [doi: 10.2105/AJPH.2011.300219].

Prinzing, Friedrich 1931: Handbuch der medizinischen Statistik. Zweiter Halbband: Die Sterbefälle. Jena: Gustav Fischer.

Reuser, Mieke; Bonneux, Luc G.; Willekens, Frans J. 2009: Smoking kills, obesity disables: a multistate approach of the US Health and Retirement Survey. In: Obesity 17,4: 783-789 [doi: 10.1038/oby.2008.640].

Reuser, Mieke; Bonneux, Luc; Willekens, Frans J. 2008: The burden of mortality of obesity at middle and old age is small. A life table analysis of the US Health and Retirement Survey. In: European Journal of Epidemiology 23,9: 601-607 [doi: 10.1007/ s10654-008-9269-8].

Reuser, Mieke; Willekens, Frans J.; Bonneux, Luc 2011: Higher education delays and shortens cognitive impairment. A multistate life table analysis of the US Health and Retirement Study. In: European Journal of Epidemiology 26,5: 395-403 [doi: 10.1007/ s10654-011-9553-x].

Ritz, Hans-Günther 1992: Soziale Ungleichheit vor Tod in der Bundesrepublik Deutschland. Gesundheit - Arbeit - Medizin 3. Bremerhaven: Wirtschaftsverlag NW, Verlag für neue Wissenschaft $\mathrm{GmbH}$.

Salzmann, Thomas; Bohk, Christina 2008: Überprüfung der im Rahmen des „Lebenserwartungssurveys" gemessenen Sterblichkeit auf Bevölkerungsrepräsentativität unter Berücksichtigung rechts- und intervallzensierter Ereignisse mit dem Konzept "Relative Survival“. In: Zeitschrift für Bevölkerungswissenschaft 33,2: 121-152 [doi: 10.1007/ s12523-009-0008-3].

Schimany, Peter 2003: Die Alterung der Gesellschaft. Ursachen und Folgen des demographischen Umbruchs. Frankfurt am Main: Campus.

Schmid, Josef; Heigl, Andreas; Mai, Ralf 2000: Sozialprognose. Die Belastung der nachwachsenden Generation. München: Olzog.

Schneider, Sven 2008: Der Schichtgradient von Morbidität und Mortalität. Vorschlag für ein theoretisches Erklärungsmodell gesundheitlicher Ungleichheit. In: Österreichische Zeitschrift für Soziologie 33,1: 43-66 [doi: 10.1007/s11614-008-0003-2]. 
Schnell, Rainer; Trappmann, Mark 2006: Konsequenzen der Panelmortalität im SOEP für Schätzungen der Lebenserwartung. Arbeitspapier 2/2006. Konstanz: Universität Konstanz.

Shkolnikov, Vladimir M. et al. 2006: The changing relation between education and life expectancy in central and eastern Europe in the 1990s. In: Journal of Epidemiology and Community Health 60,10: 875-881 [doi: 10.1136/jech.2005.044719].

Shkolnikov, Vladimir M. et al. 2008: Length of life and the pensions of five million retired German men. In: European Journal of Public Health 18,3: 264-269 [doi: 10.1093/eurpub/ckm102].

Spijker, Jeroen 2004: Socioeconomic determinants of regional mortality differences in Europe. Amsterdam: Dutch University Press.

Spoerri, Adrian et al. 2006: Educational inequalities in life expectancy in the German speaking part of Switzerland between 1990 and 1997: Swiss National Cohort. In: Swiss Medical Weekly 136: 145-148 [doi: 10.5167/uzh-81153].

Spree, Reinhard 1981: Soziale Ungleichheit vor Krankheit und Tod. Zur Sozialgeschichte des Gesundheitsbereichs im Deutschen Kaiserreich. Göttingen: Vandenhoeck \& Ruprecht.

Statistisches Bundesamt 1992: Klassifikation der Berufe 1992 (KIdB 92). Gliederungsstruktur bis zur 4 Steller-Ebene. Wiesbaden: Statistisches Bundesamt.

Statistisches Bundesamt 2006: Generationensterbetafeln für Deutschland. Modellrechnungen für die Geburtsjahrgänge 1871-2004. Wiesbaden: Statistisches Bundesamt.

Thatcher, A. Roger; Kannisto, Väinö; Vaupel, James W. 1998: The force of mortality at ages 80 to 120. Odense Monographs on Population Aging 5. Odense: Odense University Press.

Timæus, lan M. 1991: Measurement of adult mortality in less developed countries: a comparative review. In: Population Index 57,4: 552-568.

Unger, Rainer; Schulze, Alexander 2013: Können wir (alle) überhaupt länger arbeiten? Trends in der gesunden Lebenserwartung nach Sozialschicht in Deutschland. In: Comparative Population Studies - Zeitschrift für Bevölkerungswissenschaft 38,3: 545-564 [doi: 10.4232/10.CPoS-2013-03de].

United Nations Educational Scientific and Cultural Organization 1996: International Standard Classification of Education ISCED 1997. Montreal: UNESCO-UIS.

Valkonen, Tapani et al. 1993: Socio-economic mortality differences in Finland 1981-90. Statistics Finland Population. Helsinki: Statistics Finland.

Valkonen, Tapani; Sihvonen, Ari-Pekka; Lahelma, Eero 1997: Health expectancy by level of education in Finland. In: Social Science \& Medicine 44,6: 801-808.

Van Den Hout, Ardo; Jagger, Carol; Matthews, Fiona E. 2009: Estimating life expectancy in health and ill health by using a hidden Markov model. In: Journal of the Royal Statistical Society: Series C (Applied Statistics) 58,4: 449-465 [doi: 10.1111/j.14679876.2008.00659.x].

von Gaudecker, Hans-Martin 2006: Differentielle Sterblichkeit in der GRV: Problemaufriss und erste Berechnungen. In: Deutsche Rentenversicherung Bund (Ed.): Forschungsrelevante Daten der Rentenversicherung: Bericht vom zweiten Workshop des Forschungsdatenzentrums der Rentenversicherung (FDZ-RV) vom 27. bis 29. Juni 2005 in Würzburg. DRV-Schriften 55. Bad Homburg: Wdv Gesellschaft für Medien und Kommunikation: 242-252. 
von Gaudecker, Hans-Martin; Scholz, Rembrandt D. 2007: Differential mortality by lifetime earnings in Germany. In: Demographic Research 17,4: 83-108 [doi: 10.4054/DemRes.2007.17.4].

Westergaard, Harald 1882: Die Lehre von der Mortalität und Morbilität. Anthropologisch-statistische Untersuchungen. Jena: Gustav Fischer.

Wiedemann, Angela 2012: Die Mortalität erwachsener Immigranten in Deutschland: Eine indirekte Schätzung der Sterblichkeitsunterschiede zwischen türkisch- und italienischstämmigen Einwanderern und der deutschen Bevölkerung. Diplomarbeit: Universität Wien.

Zajacova, Anna; Goldman, Noreen; Rodríguez, Germán 2009: Unobserved heterogeneity can confound the effect of education on mortality. In: Mathematical Population Studies 16,2: 153-173 [doi: 10.1080/08898480902790528].

Dr. Marc Luy ( $\triangle)$, Dr. Christian Wegner-Siegmundt, Angela Wiedemann. Wittgenstein Centre for Demography and Global Human Capital (IIASA, OEAW/VID, WU), Vienna Institute of Demography of the Austrian Academy of Sciences. Vienna, Austria.

E-mail: mail@marcluy.eu, christian.wegner@oeaw.ac.at, angela.wiedemann@oeaw.ac.at

URL: http://www.marcluy.eu

http://www.oeaw.ac.at/vid/staff/staff_christian_wegner.shtml http://www.oeaw.ac.at/vid/staff/staff_angela_wiedemann.shtml

Dr. Jeroen Spijker. Centre d'Estudis Demogràfics. Bellaterra, Spain E-mail: jspijker@ced.uab.es

URL: http://www.ced.uab.es/content/spijker-jeroen 


\section{Appendix}

Tab. A1: Average health status at the time of first survey of respondents with known and unknown survival status at the time of mortality follow-up (second survey) and unknown-known health status ratio of average health statuses for all analysed subsamples, Men

\begin{tabular}{|c|c|c|c|}
\hline \multirow[t]{2}{*}{ SEP indicator / subpopulation } & \multicolumn{2}{|c|}{ Survival status } & \multirow{2}{*}{$\begin{array}{l}\text { Unknown- } \\
\text { known ratio }\end{array}$} \\
\hline & Known & Unknown & \\
\hline All men & 2.67 & 2.66 & 0.99 \\
\hline \multicolumn{4}{|l|}{ Education according to ISCED-97 ${ }^{1}$} \\
\hline Low (ISCED 1-2) & 2.94 & 2.95 & 1.00 \\
\hline Medium (ISCED 3-4) & 2.70 & 2.69 & 1.00 \\
\hline High (ISCED 5-6) & 2.46 & 2.38 & 0.97 \\
\hline \multicolumn{4}{|l|}{ Household net income } \\
\hline $1^{\text {st }}$ quartile (below $€ 895$ ) & 2.85 & 2.85 & 1.00 \\
\hline $2^{\text {nd }}$ quartile $(€ 895-1,406)$ & 2.73 & 2.68 & 0.98 \\
\hline $3^{\text {rd }}$ quartile $(€ 1,406-1,917)$ & 2.63 & 2.70 & 1.03 \\
\hline $4^{\text {th }}$ quartile ( $€ 1,917$ and more) & 2.48 & 2.41 & 0.97 \\
\hline \multicolumn{4}{|l|}{ Work status } \\
\hline Manual workers (all) & 2.85 & 2.79 & 0.98 \\
\hline Unskilled or semi-skilled workers & 2.95 & 2.95 & 1.00 \\
\hline Skilled workers & 2.82 & 2.72 & 0.96 \\
\hline Master craftsmen, overseers, foremen & 2.67 & 2.42 & 0.91 \\
\hline Employees (all) & 2.60 & 2.51 & 0.96 \\
\hline Simple tasks & 3.12 & 2.90 & 0.93 \\
\hline Qualified tasks & 2.67 & 2.68 & 1.00 \\
\hline Highly qualified tasks & 2.47 & 2.30 & 0.93 \\
\hline Public servants (all) & 2.50 & 2.56 & 1.02 \\
\hline Simple or medium service & 2.60 & 2.39 & 0.92 \\
\hline Higher or senior service & 2.40 & 2.61 & 1.09 \\
\hline Self-employed workers (all) & 2.57 & 2.57 & 1.00 \\
\hline Entrepreneurs & 2.66 & 2.67 & 1.01 \\
\hline Freelancers & 2.45 & 2.17 & 0.89 \\
\hline Farmers & 2.49 & 2.57 & 1.03 \\
\hline \multicolumn{4}{|l|}{ Vocational classes acc. to KIdB-92 (Germany) ${ }^{2}$} \\
\hline Jobs in (animal) husbandry, forestry, horticulture & 2.62 & 2.62 & 1.00 \\
\hline Miners and mineral workers & 3.51 & 4.06 & 1.16 \\
\hline Production jobs (all) & 2.80 & 2.76 & 0.98 \\
\hline Metal production and metal working & 2.76 & 2.76 & 1.00 \\
\hline Metal constr., mech. engineering and similar & 2.66 & 2.68 & 1.01 \\
\hline Electrical engineering & 2.74 & 2.61 & 0.95 \\
\hline
\end{tabular}


Tab. A1: Continuation

\begin{tabular}{|c|c|c|c|}
\hline \multirow[t]{2}{*}{ SEP indicator / subpopulation } & \multicolumn{2}{|c|}{ Survival status } & \multirow{2}{*}{$\begin{array}{l}\text { Unknown- } \\
\text { known ratio }\end{array}$} \\
\hline & Known & Unknown & \\
\hline Textile sector & 3.28 & 2.71 & 0.83 \\
\hline Foodstuffs sector & 2.70 & 2.53 & 0.94 \\
\hline Structural and civil engineering & 2.96 & 2.40 & 0.81 \\
\hline Wood and plastics processing & 2.86 & 2.94 & 1.03 \\
\hline Painting, varnishing and similar occupations & 2.60 & 2.60 & 1.00 \\
\hline Unskilled workers without specification & 2.96 & 3.11 & 1.05 \\
\hline Technical occupations (all) & 2.50 & 2.49 & 1.00 \\
\hline Engineering, chemistry, physics, maths & 2.44 & 2.23 & 0.92 \\
\hline Technicians, technical specialists & 2.55 & 2.56 & 1.00 \\
\hline Service sector (all) & 2.61 & 2.62 & 1.00 \\
\hline Goods und service marketing & 2.69 & 2.59 & 0.96 \\
\hline Transport industry & 2.77 & 2.63 & 0.95 \\
\hline Organisation, administration, clerical jobs & 2.57 & 2.54 & 0.99 \\
\hline Public and private security sector & 2.53 & 2.40 & 0.95 \\
\hline Health sector & 2.35 & 2.23 & 0.95 \\
\hline Social service and education & 2.45 & 2.77 & 1.13 \\
\hline Other service occupations & 2.60 & 2.71 & 1.04 \\
\hline Other work force & 2.94 & 3.35 & 1.14 \\
\hline
\end{tabular}

Notes: Health status is measured by means of self-perceived health ("How is your health in general?" Very good $=1$ / good $=2$ / satisfactory $=3$ / not so good $=4$ / poor $=5$ ); Average health statuses are age standardized with the total male LES population in 5 -year age groups as standard (known + unknown survival status); Subpopulations with case numbers of five or less among individuals with known or unknown survival status are marked in italic; None of the differences in average health status between individuals with known and unknown survival status at the time of mortality follow-up is statistically significant (95 percent confidence level); Figures exclude LES participants below age 33 at the time of the first survey.

${ }^{1}$ ISCED-97 = International Standard Classification of Education

${ }^{2} \mathrm{KldB}-92=$ German Classification of Professions

Source: own calculations with LES data 
Tab. A2: Average health status at the time of first survey of respondents with known and unknown survival status at the time of mortality follow-up (second survey) and unknown-known health status ratio of average health statuses for all analysed subsamples, Women

\begin{tabular}{|c|c|c|c|}
\hline \multirow[t]{2}{*}{ SEP indicator / subpopulation } & \multicolumn{2}{|c|}{ Survival status } & \multirow{2}{*}{$\begin{array}{l}\text { Unknown- } \\
\text { known ratio }\end{array}$} \\
\hline & Known & Unknown & \\
\hline All women & 2.78 & 2.82 & 1.01 \\
\hline \multicolumn{4}{|l|}{ Education according to ISCED-97 ${ }^{1}$} \\
\hline Low (ISCED 1-2) & 2.86 & 2.88 & 1.01 \\
\hline Medium (ISCED 3-4) & 2.76 & 2.81 & 1.02 \\
\hline High (ISCED 5-6) & 2.53 & 2.39 & 0.94 \\
\hline \multicolumn{4}{|l|}{ Household net income } \\
\hline $1^{\text {st }}$ quartile (below $€ 895$ ) & 2.91 & 2.86 & 0.98 \\
\hline $2^{\text {nd }}$ quartile $(€ 895-1,406)$ & 2.85 & 2.84 & 1.00 \\
\hline $3^{\text {rd }}$ quartile $(€ 1,406-1,917)$ & 2.78 & 2.92 & 1.05 \\
\hline $4^{\text {th }}$ quartile ( $€ 1,917$ and more) & 2.60 & 2.60 & 1.00 \\
\hline \multicolumn{4}{|l|}{ Work status } \\
\hline Manual workers (all) & 2.90 & 2.93 & 1.01 \\
\hline Unskilled or semi-skilled workers & 2.91 & 2.92 & 1.00 \\
\hline Skilled workers & 2.88 & 2.92 & 1.02 \\
\hline Master craftsmen, overseers, foremen & 2.71 & 2.70 & 1.00 \\
\hline Employees (all) & 2.71 & 2.72 & 1.00 \\
\hline Simple tasks & 2.80 & 2.75 & 0.98 \\
\hline Qualified tasks & 2.63 & 2.66 & 1.01 \\
\hline Highly qualified tasks & 2.66 & 2.61 & 0.98 \\
\hline Public servants (all) & 2.71 & 2.38 & 0.88 \\
\hline Simple or medium service & 2.77 & 2.40 & 0.87 \\
\hline Higher or senior service & 2.54 & 2.24 & 0.88 \\
\hline Self-employed workers (all) & 2.81 & 2.83 & 1.01 \\
\hline Entrepreneurs & 2.67 & 2.73 & 1.02 \\
\hline Freelancers & 2.60 & 2.91 & 1.12 \\
\hline Farmers & 3.20 & 3.05 & 0.96 \\
\hline \multicolumn{4}{|l|}{ Vocational classes acc. to KIdB-92 (Germany) ${ }^{2}$} \\
\hline Jobs in (animal) husbandry, forestry, horticulture & 2.79 & 3.05 & 1.10 \\
\hline Miners and mineral workers & 3.00 & 2.00 & 0.67 \\
\hline Production jobs (all) & 2.88 & 2.89 & 1.00 \\
\hline Metal production and metal working & 3.10 & 3.00 & 0.97 \\
\hline Metal constr., mech. engineering and similar & 3.02 & 3.36 & 1.11 \\
\hline Electrical engineering & 2.19 & 3.80 & 1.74 \\
\hline
\end{tabular}


Tab. A2: Continuation

\begin{tabular}{|c|c|c|c|}
\hline \multirow[t]{2}{*}{ SEP indicator / subpopulation } & \multicolumn{2}{|c|}{ Survival status } & \multirow{2}{*}{$\begin{array}{l}\text { Unknown- } \\
\text { known ratio }\end{array}$} \\
\hline & Known & Unknown & \\
\hline Textile sector & 2.83 & 2.74 & 0.97 \\
\hline Foodstuffs sector & 2.79 & 2.97 & 1.07 \\
\hline Structural and civil engineering & --- & 3.00 & --- \\
\hline Wood and plastics processing & 3.00 & 5.00 & 1.67 \\
\hline Painting, varnishing and similar occupations & 3.68 & --- & --- \\
\hline Unskilled workers without specification & 2.87 & 2.95 & 1.03 \\
\hline Technical occupations (all) & 2.63 & 1.86 & 0.71 \\
\hline Engineering, chemistry, physics, maths & 2.35 & --- & --- \\
\hline Technicians, technical specialists & 2.65 & 1.86 & 0.70 \\
\hline Service sector (all) & 2.74 & 2.76 & 1.01 \\
\hline Goods und service marketing & 2.81 & 2.81 & 1.00 \\
\hline Transport industry & 2.76 & 2.72 & 0.98 \\
\hline Organisation, administration, clerical jobs & 2.71 & 2.70 & 1.00 \\
\hline Public and private security sector & 2.79 & 2.66 & 0.95 \\
\hline Health sector & 2.58 & 2.57 & 1.00 \\
\hline Social service and education & 2.66 & 2.52 & 0.95 \\
\hline Other service occupations & 2.83 & 2.85 & 1.00 \\
\hline Other work force & 2.74 & 2.68 & 0.98 \\
\hline
\end{tabular}

Notes: Health status is measured by means of self-perceived health ("How is your health in general?" Very good=1/good=2 / satisfactory=3 / not so good=4 / poor $=5$ ); Average health statuses are age standardized with the total female LES population in 5-year age groups as standard (known + unknown survival status); Subpopulations with case numbers of five or less among individuals with known or unknown survival status are marked in italic; None of the differences in average health status between individuals with known and unknown survival status at the time of mortality follow-up is statistically significant (95 percent confidence level); Figures exclude LES participants below age 33 at the time of the first survey.

${ }^{1}$ ISCED-97 = International Standard Classification of Education

${ }^{2} \mathrm{KldB}-92=$ German Classification of Professions

Source: own calculations with LES data 
Tab. A3: Number of respondents $R$, number of deaths $D$, average age at the time of first survey $\bar{x}$, average survival time $\bar{z}$ until the mortality follow-up, and respondents' survival rate $\dot{S}_{R}(\bar{x}, \bar{x}+\bar{z})$ for the total subsamples, Men

\begin{tabular}{|c|c|c|c|c|c|}
\hline SEP indicator / subpopulation & $R$ & $D$ & $\bar{x}$ & $\bar{z}$ & $\hat{S}_{R}$ \\
\hline \multicolumn{5}{|l|}{ Education according to ISCED-97' } & 0.8065 \\
\hline Low (ISCED 1-2) & 448 & 123 & 52.51 & 13.09 & 0.7254 \\
\hline Medium (ISCED 3-4) & 2,165 & 442 & 50.21 & 13.12 & 0.7958 \\
\hline High (ISCED 5-6) & 748 & 85 & 48.01 & 13.08 & 0.8864 \\
\hline \multicolumn{6}{|l|}{ Household net income } \\
\hline $1^{\text {st }}$ quartile (below $€ 895$ ) & 747 & 232 & 52.86 & 13.12 & 0.6894 \\
\hline $2^{\text {nd }}$ quartile $(€ 895-1,406)$ & 1,091 & 196 & 49.63 & 13.13 & 0.8203 \\
\hline $3^{\text {rd }}$ quartile $(€ 1,406-1,917)$ & 744 & 115 & 48.52 & 13.06 & 0.8454 \\
\hline $4^{\text {th }}$ quartile $(€ 1,917$ and more $)$ & 692 & 89 & 49.16 & 13.10 & 0.8714 \\
\hline \multicolumn{6}{|l|}{ Work status } \\
\hline Manual workers (all) & 1,282 & 305 & 50.31 & 13.11 & 0.7621 \\
\hline Unskilled or semi-skilled workers & 471 & 139 & 51.69 & 13.12 & 0.7049 \\
\hline Skilled workers & 558 & 110 & 49.03 & 13.12 & 0.8029 \\
\hline Master craftsmen, overseers, foremen & 253 & 56 & 50.60 & 13.06 & 0.7787 \\
\hline Employees (all) & 1,121 & 168 & 49.34 & 13.10 & 0.8501 \\
\hline Simple tasks & 104 & 30 & 51.40 & 13.06 & 0.7115 \\
\hline Qualified tasks & 459 & 70 & 48.60 & 13.15 & 0.8475 \\
\hline Highly qualified tasks & 558 & 68 & 49.57 & 13.07 & 0.8781 \\
\hline Public servants (all) & 392 & 73 & 51.25 & 13.09 & 0.8138 \\
\hline Simple or medium service & 218 & 46 & 50.40 & 13.13 & 0.7890 \\
\hline Higher or senior service & 277 & 35 & 48.60 & 13.14 & 0.8736 \\
\hline Self-employed workers (all) & 495 & 81 & 49.39 & 13.14 & 0.8364 \\
\hline Entrepreneurs & 185 & 41 & 51.70 & 13.08 & 0.7784 \\
\hline Freelancers & 109 & 17 & 50.22 & 13.02 & 0.8440 \\
\hline Farmers & 93 & 14 & 51.37 & 13.17 & 0.8495 \\
\hline \multicolumn{6}{|l|}{ Vocational classes acc. to KIdB-92 (Germany) ${ }^{2}$} \\
\hline Jobs in (animal) husbandry, forestry, horticulture & 126 & 27 & 50.48 & 13.17 & 0.7857 \\
\hline Miners and mineral workers & 26 & 11 & 55.35 & 13.22 & 0.5769 \\
\hline Production jobs (all) & 996 & 216 & 49.86 & 13.11 & 0.7831 \\
\hline Metal production and metal working & 73 & 14 & 49.21 & 13.09 & 0.8082 \\
\hline Metal constr., mech. engineering and similar & 277 & 57 & 48.53 & 13.12 & 0.7942 \\
\hline Electrical engineering & 84 & 16 & 46.40 & 13.06 & 0.8095 \\
\hline
\end{tabular}


Tab. A3: Continuation

\begin{tabular}{lrrrrr}
\hline SEP indicator / subpopulation & $R$ & $D$ & $\bar{x}$ & $\bar{z}$ & $\hat{S}_{R}$ \\
\hline Textile sector & 14 & 3 & 54.36 & 13.07 & 0.7857 \\
Foodstuffs sector & 44 & 8 & 49.09 & 13.09 & 0.8182 \\
Structural and civil engineering & 126 & 33 & 50.76 & 13.13 & 0.7381 \\
Wood and plastics processing & 51 & 14 & 55.78 & 13.04 & 0.7255 \\
Painting, varnishing and similar occupations & 47 & 8 & 49.11 & 13.11 & 0.8298 \\
Unskilled workers without specification & 61 & 21 & 53.13 & 13.13 & 0.6557 \\
Technical occupations (all) & 364 & 40 & 49.49 & 13.14 & 0.8901 \\
Engineering, chemistry, physics, maths & 146 & 16 & 50.16 & 13.17 & 0.8904 \\
Technicians, technical specialists & 218 & 24 & 49.05 & 13.12 & 0.8899 \\
Service sector (all) & 1,553 & 277 & 49.57 & 13.11 & 0.8216 \\
Goods und service marketing & 294 & 54 & 49.33 & 13.06 & 0.8163 \\
Transport industry & 258 & 63 & 50.09 & 13.13 & 0.7558 \\
Organisation, administration, clerical jobs & 563 & 100 & 50.16 & 13.13 & 0.8224 \\
Public and private security sector & 160 & 35 & 49.97 & 13.13 & 0.7813 \\
Health sector & 46 & 5 & 49.17 & 13.16 & 0.8913 \\
Social service and education & 159 & 12 & 46.61 & 13.09 & 0.9245 \\
Other service occupations & 39 & 6 & 50.51 & 12.97 & 0.8462 \\
Other work force & 71 & 15 & 50.28 & 12.94 & 0.7887 \\
\hline
\end{tabular}

Note: Figures exclude LES participants below age 33 at the time of first survey.

1 ISCED-97 = International Standard Classification of Education

${ }^{2}$ KldB-92 = German Classification of Professions

Source: own calculations with LES data 
Tab. A4: Number of respondents $R$, number of deaths $D$, average age at the time of first survey $\bar{x}$, average survival time $\bar{z}$ until the mortality follow-up, and respondents' survival rate $\ddot{S}_{R}(\bar{x}, \bar{x}+\bar{z})$ for the total subsamples, Women

\begin{tabular}{|c|c|c|c|c|c|}
\hline SEP indicator / subpopulation & $R$ & $D$ & $\bar{x}$ & $\bar{z}$ & $\hat{S}_{R}$ \\
\hline All women & 3,044 & 304 & 50.05 & 13.11 & 0.9001 \\
\hline \multicolumn{6}{|l|}{ Education according to ISCED-97 ${ }^{1}$} \\
\hline Low (ISCED 1-2) & 1,215 & 146 & 52.46 & 13.13 & 0.8798 \\
\hline Medium (ISCED 3-4) & 1,630 & 150 & 48.78 & 13.10 & 0.9080 \\
\hline High (ISCED 5-6) & 196 & 8 & 45.45 & 13.15 & 0.9592 \\
\hline \multicolumn{6}{|l|}{ Household net income } \\
\hline $1^{\text {st }}$ quartile (below $€ 895$ ) & 867 & 142 & 54.32 & 13.12 & 0.8362 \\
\hline $2^{\text {nd }}$ quartile $(€ 895-1,406)$ & 930 & 93 & 49.45 & 13.13 & 0.9000 \\
\hline $3^{\text {rd }}$ quartile $(€ 1,406-1,917)$ & 599 & 29 & 47.06 & 13.09 & 0.9516 \\
\hline $4^{\text {th }}$ quartile $(€ 1,917$ and more $)$ & 528 & 25 & 47.31 & 13.09 & 0.9527 \\
\hline \multicolumn{6}{|l|}{ Work status } \\
\hline Manual workers (all) & 842 & 96 & 50.27 & 13.13 & 0.8860 \\
\hline Unskilled or semi-skilled workers & 726 & 83 & 50.39 & 13.12 & 0.8857 \\
\hline Skilled workers & 108 & 13 & 49.18 & 13.18 & 0.8796 \\
\hline Master craftsmen, overseers, foremen & 8 & 0 & 53.88 & 13.41 & 1.0000 \\
\hline Employees (all) & 1,348 & 119 & 48.59 & 13.09 & 0.9117 \\
\hline Simple tasks & 626 & 67 & 49.61 & 13.12 & 0.8930 \\
\hline Qualified tasks & 616 & 42 & 47.96 & 13.06 & 0.9318 \\
\hline Highly qualified tasks & 106 & 10 & 46.20 & 13.07 & 0.9057 \\
\hline Public servants (all) & 259 & 24 & 51.31 & 13.13 & 0.9073 \\
\hline Simple or medium service & 35 & 5 & 50.09 & 13.14 & 0.8571 \\
\hline Higher or senior service & 87 & 0 & 42.40 & 13.14 & 1.0000 \\
\hline Self-employed workers (all) & 122 & 5 & 44.61 & 13.14 & 0.9590 \\
\hline Entrepreneurs & 83 & 6 & 50.73 & 13.14 & 0.9277 \\
\hline Freelancers & 27 & 1 & 46.56 & 13.13 & 0.9630 \\
\hline Farmers & 61 & 9 & 55.16 & 13.13 & 0.8525 \\
\hline \multicolumn{6}{|l|}{ Vocational classes acc. to KIdB-92 (Germany) ${ }^{2}$} \\
\hline Jobs in (animal) husbandry, forestry, horticulture & 60 & 4 & 50.77 & 13.23 & 0.9333 \\
\hline Miners and mineral workers & 1 & 0 & 56.00 & 12.21 & 1.0000 \\
\hline Production jobs (all) & 387 & 41 & 50.94 & 13.17 & 0.8941 \\
\hline Metal production and metal working & 5 & 0 & 48.40 & 13.13 & 1.0000 \\
\hline Metal constr., mech. engineering and similar & 7 & 1 & 48.29 & 13.15 & 0.8571 \\
\hline Electrical engineering & 5 & 3 & 57.20 & 13.23 & 0.4000 \\
\hline
\end{tabular}


Tab. A4: Continuation

\begin{tabular}{lrrrrr}
\hline SEP indicator / subpopulation & $R$ & $D$ & $\overline{\mathrm{x}}$ & $\overline{\mathrm{z}}$ & $\hat{S}_{R}$ \\
\hline Textile sector & 136 & 14 & 51.72 & 13.11 & 0.8971 \\
Foodstuffs sector & 34 & 2 & 49.74 & 13.24 & 0.9412 \\
Structural and civil engineering & 0 & 0 & --- & --- & --- \\
Wood and plastics processing & 1 & 0 & 62.00 & 13.19 & 1.0000 \\
Painting, varnishing and similar occupations & 3 & 0 & 46.00 & 13.49 & 1.0000 \\
Unskilled workers without specification & 96 & 13 & 49.54 & 13.22 & 0.8646 \\
Technical occupations (all) & 56 & 5 & 49.88 & 12.92 & 0.9107 \\
Engineering, chemistry, physics, maths & 5 & 2 & 53.00 & 12.56 & 0.6000 \\
Technicians, technical specialists & 51 & 3 & 49.57 & 12.95 & 0.9412 \\
Service sector (all) & 1,879 & 157 & 48.21 & 13.11 & 0.9164 \\
Goods und service marketing & 390 & 32 & 48.17 & 13.14 & 0.9179 \\
Transport industry & 67 & 7 & 48.30 & 13.17 & 0.8955 \\
Organisation, administration, clerical jobs & 709 & 56 & 48.26 & 13.08 & 0.9210 \\
Public and private security sector & 14 & 2 & 49.93 & 13.14 & 0.8571 \\
Health sector & 145 & 13 & 46.63 & 13.04 & 0.9103 \\
Social service and education & 172 & 6 & 45.56 & 13.13 & 0.9651 \\
Other service occupations & 358 & 41 & 49.85 & 13.15 & 0.8855 \\
Other work force & 43 & 8 & 50.72 & 12.98 & 0.8140 \\
\hline
\end{tabular}

Note: Figures exclude LES participants below age 33 at the time of the first survey.

1 ISCED-97 = International Standard Classification of Education

${ }^{2}$ KldB-92 = German Classification of Professions

Source: own calculations with LES data 


\section{Comparative Population Studies}

WWW.comparativepopulationstudies.de

ISSN: 1869-8980 (Print) - 1869-8999 (Internet)

Published by / Herausgegeben von

Prof. Dr. Norbert F. Schneider

Federal Institute for Population Research

D-65180 Wiesbaden / Germany

\section{Managing Editor /}

Verantwortlicher Redakteur

Frank Swiaczny

\section{Assistant Managing Editor /}

\section{Stellvertretende Redakteurin}

Katrin Schiefer

\section{Copy Editor (German) /}

Lektorat (deutsch)

Dr. Evelyn Grünheid

\section{Layout / Satz}

Beatriz Feiler-Fuchs

E-mail:cpos@bib.bund.de

\section{Scientific Advisory Board /}

Wissenschaftlicher Beirat

Paul Gans (Mannheim)

Johannes Huinink (Bremen)

Michaela Kreyenfeld (Rostock)

Marc Luy (Wien)

Clara H. Mulder (Groningen)

Notburga Ott (Bochum)

Peter Preisendörfer (Mainz)

Zsolt Spéder (Budapest)
Board of Reviewers / Gutachterbeirat Martin Abraham (Erlangen)

Laura Bernardi (Lausanne)

Hansjörg Bucher (Bonn)

Claudia Diehl (Konstanz)

Andreas Diekmann (Zürich)

Gabriele Doblhammer-Reiter (Rostock)

Jürgen Dorbritz (Wiesbaden)

Anette Eva Fasang (Berlin)

E.-Jürgen Flöthmann (Bielefeld)

Alexia Fürnkranz-Prskawetz (Wien)

Beat Fux (Salzburg)

Joshua Goldstein (Berkeley)

Karsten Hank (Köln)

Sonja Haug (Regensburg)

Hill Kulu (Liverpool)

Aart C. Liefbroer (Den Haag)

Kurt Lüscher (Konstanz)

Emma Lundholm (Umeå)

Nadja Milewski (Rostock)

Dimiter Philipov (Wien)

Roland Rau (Rostock)

Tomáš Sobotka (Wien)

Jeroen Spijker (Barcelona)

Olivier Thévenon (Paris)

Helga de Valk (Brussel)

Heike Trappe (Rostock)

Michael Wagner (Köln) 